\title{
Steady-state response of fluid-structure interactions in hydraulic piping system of passive interconnected suspensions
}

\section{Jing Zhao*, Nong Zhang and JinChen Ji}

\author{
School of Electrical, Mechanical \\ and Mechatronic Systems, FEIT, \\ University of Technology Sydney, \\ Broadway, NSW 2007, Australia \\ Email: Jing.Zhao-3@alumni.uts.edu.au \\ Email: Nong.Zhang@uts.edu.au \\ Email: Jin.Ji@uts.edu.au \\ ${ }^{*}$ Corresponding author
}

\begin{abstract}
Pressure changes in the liquid-filled fluid circuit of a hydraulically interconnected suspension (HIS) system can induce vibrations of the whole pipeline and the associated structure, and hence become a source of structural noise which degrades ride comfort. This paper presents a numerical and experimental investigation into the vibration of the hydraulic piping system of a passive interconnected suspension. The transfer matrix method (TMM) is used to develop a mathematical model, which consists of various pipe sections, hose sections, concentrated masses, spring supports, elbows, damper valves, and accumulators. Laboratory experiments are performed on two liquid-filled piping systems. The measured steady-state responses of the hydraulic circuits are compared with those obtained from numerical simulations of the developed model. It is found that the developed model of the hydraulic system has a reasonable accuracy in the frequency range of interest, and thus can be employed to optimise the design of the hydraulic system.
\end{abstract}

Keywords: fluid-structure coupled vibration; liquid-filled piping system; passive interconnected suspension; TMM; transfer matrix method.

Reference to this paper should be made as follows: Zhao, J., Zhang, N. and Ji, J. (2016) 'Steady-state response of fluid-structure interactions in hydraulic piping system of passive interconnected suspensions', Int. J. Vehicle Design, Vol. 72, No. 4, pp.305-331.

Biographical notes: Jing Zhao received her BE in 1996 from the University of Chongqing, China, ME in 2007 from the University of New South Wales, and $\mathrm{PhD}$ in 2014 from the University of Technology Sydney. She worked at structure design and manufacture institute in China before coming to Australia. Now, she is working at the University of Technology Sydney. Her research interests include vehicle dynamics and control, industrial engineering, and operational reliability.

Nong Zhang received $\mathrm{PhD}$ in 1989 from the University of Tokyo and worked at several universities in China, Japan, USA and Australia before joining University of Technology, Sydney in 1995. Since 2009, he has been the Professor of Mechanical Engineering, at School of Electrical, Mechanical and Mechatronic Systems, University of Technology Sydney. He focused on fundamental research on mechanical vibration, multi-body system dynamics 
and its applications to complex machines and vehicular systems. He developed advanced models and numerical schemes for simulating gear shift in powertrains with AT, MT and CVTs and for dynamic analysis of vehicles fitted with advanced suspensions.

JinChen Ji is currently an Associate Professor of Mechanical Engineering at University of Technology Sydney. He has extensive research experience in the dynamics, vibration and control of mechanical systems. His current research interests include nonlinear dynamics and bifurcation control of nonlinear mechanical systems, vehicle system dynamics, dynamics and vibration of wind turbines, consensus and synchronisation of networked systems, stability and dynamics of time-delayed nonlinear systems, design of nonlinear vibration absorbers, and rotor-bearing dynamics.

\section{Introduction}

Hydraulically interconnected suspension (HIS) systems have been successfully applied to rally cars and passenger vehicles to improve anti-roll performance. Figure 1 shows the basic structure of the HIS system installed on the front half of a car. The hydraulic circuit consists of double-acting cylinders, diaphragm-type hydraulic accumulators, damper valves, steel pipes and rubber hoses. When installed on a vehicle, the pistons of the cylinders are attached to the wheel hubs while the cylinders and the hydraulic circuits are mounted on the vehicle chassis. When the vehicle vibrates in the vertical direction, the relative movement between the vehicle body and its wheels result in relative movement between the cylinders and pistons. The pressure ripple induced by the movement is propagated within the hydraulic circuit and generates objectionable vibrations. The vibrations can be transferred to the vehicle structure and become an excitation force to the vehicle. The low- and mid-frequency vibrations can influence vehicle handling and ride comfort whilst the high-frequency vibrations are associated with vehicle noise.

Figure 1 Schematic diagram of a half-car HIS system

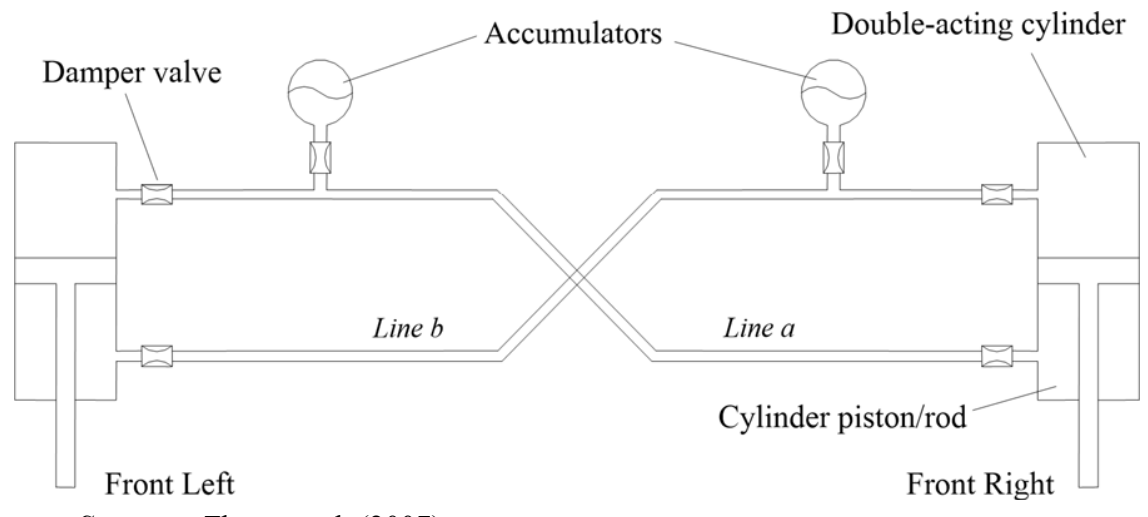

Source: Zhang et al. (2007)

The level of noise, vibration and harshness (NVH) is an important quality indicator of a passenger car and should be minimised to the lowest level possible. 
An experimentally validated mathematical model of the hydraulic piping system is investigated in this paper to develop a deep understanding of the system dynamics and to provide a theoretical basis for optimising the structure design and assembly details. This paper is organised into six sections. A literature review is presented in Section 2. Sections 3 and 4 give the mathematical modelling and experimental results of the developed model respectively. The effects of the piping system on system dynamics are studied in Section 5 and the conclusion is given in Section 6.

\section{Literature review}

This section provides the research background on passive HISs and the modelling of hydraulic components.

\subsection{Interconnected suspension system}

Various interconnected suspension systems have been applied to vehicles in an attempt to reduce the possibility of roll incidents, which include the hydragas suspension system (Rideout and Anderson, 2003), active interconnected suspension (Iijima, 1993), hydro-pneumatic suspension system, and hydraulic system. Liu et al. used a hydraulic interconnection system to increase the roll stiffness of one pair of wheel stations (Liu et al., 1995a, 1995b; Rakheja et al., 1993). Ortiz (1997) and Zapletal (2000) presented some possible four-wheel interconnection arrangements, each comprising hydraulic circuits combined with mechanical linkages. Fontdecaba and Buj (2002) proposed a four-wheel interconnection scheme and showed that the hydraulic implementation achieved the design goals of the scheme. Mace (2004) demonstrated a theoretical study of the existing passive interconnected suspension systems, using network theory and system synthesis. Smith and Walker (2005) presented their interconnected suspension concept with possible realisation methods, both mechanical and hydraulic.

Wilde et al. (2005) performed systematic experiments of vehicle handling and compared the results of a HIS system with the performance of a conventional suspension, and found that the HIS can provide greater rollover resistance than the conventional suspension system without significantly sacrificing ride quality. Mavroudakis and Eberhard (2006) studied the performance of a four-wheel hydraulic interconnection scheme with all modes decoupled. Smith (2009) investigated the Kinetic H2 suspension in the frequency domain and analysed the ride performance of the system. The fluidstructure interaction (FSI) in the piping system was not considered in the existing research for the sake of simplicity. However, the FSI phenomenon cannot be ignored when investigating high-frequency vibrations within the hydraulic system. Therefore, the FSI of a hydraulic system is analysed in this paper.

\subsection{Hydraulic components and circuits}

The characteristics of individual hydraulic elements were investigated by Edge and Johnston (1991) and Johnston and Edge (1991), focusing on the resistance coefficients of hydraulic elements such as valves and accumulators. The dynamic pressure characteristics of hydraulic circuits were investigated before deriving these coefficients 
(Johnston and Edge, 1989). Drew et al. (1997) established a model for the hose with tuners in the power steering systems of vehicles by using the impedance matrix. The transmission mechanisms in lateral and torsional directions, namely bending and torsional waves, were considered by Longmore and Schlesinger (1991a, 1991b). Longmore et al. (1997) and Johnston et al. (2007) presented several methods to obtain the dynamic material properties of flexible hoses used in all types of theoretical models. The hose properties were obtained by measuring the impedance characteristics relating to longitudinal waves.

There are other studies that concern the dynamic analysis of fluid-filled flexible hoses. Yu and Kojima (1998) developed an analytical hose model in the transfer matrix form and determined the mechanical properties of the hose wall. Evans and Wilcox (2002) presented a model for a specific type of hose that was designed to withstand high operating pressures. The material properties and the dynamic behaviour of plastic pipes were investigated by Prek (2007).

In the analysis of the HIS system, Mrad et al. (1994) developed a quarter-car model of a hydraulic active suspension system, which includes the pump, accumulator, valves and other hydraulic elements. This was probably the first system model for the hydraulic circuit that combines the models of hydraulic elements with the pure pipe model. Some hydraulic system models were developed for particular applications. Qatu et al. (2000) established a system model for vehicle power steering that consists of a pump, hoses, tubes, and a tuned hose. A half-car model of the Kinetic $\mathrm{H} 2$ suspension was developed by Smith (2009) to investigate the suspension performance. The hydraulic system model developed in this paper will focus on the investigation of pipeline itself rather than the analysis of vehicle system performance.

\section{Mathematical modelling}

The hydraulic circuit of the HIS system can be regarded as a series of discontinuous points connected by pipes and/or hoses. The natural frequencies and mode shapes of a system are normally considered as the main characteristics to analyse the system dynamics in the frequency domain. The transfer matrix method (TMM) is employed in this study to derive the mathematical model by dividing the system into a number of subsystems interacting only with the adjacent ones. The matrices involved in the derived mathematical models are given in Appendix.

The field matrices of pipes and hoses define the forces and displacements at one section of the structure in terms of the corresponding forces and displacements at an adjacent section. One element transmits torsional waves, transverse shear and bending waves in the solid wall, and axial compression waves in both the solid wall and the liquid. The point matrices, which represent the relationship of the two sides of the discrete locations, include structural discontinuities such as concentrated masses, spring supports or elbows and fluidic discontinuities like accumulators and valves. The details of deriving the mathematical models are described in a PhD thesis (Zhao, 2014).

The entire transfer matrix of the whole system can be developed by combining the field transfer matrices and the point transfer matrices as:

$$
\mathbf{S}_{N}^{R}=\mathbf{T} \mathbf{S}_{1}^{L}+\mathbf{C},
$$


where, $\mathbf{T}=\left[\mathbf{t}_{N-1}\right]^{-1} \mathbf{P}_{N}\left(\prod_{i=N-1}^{1} \mathbf{F}_{i} \mathbf{P}_{i}\right) \mathbf{t}_{1}, \quad \mathbf{P}$ represents the point matrix, $\mathbf{F}$ indicates the field matrix, $\mathbf{S}$ stands for the state vector, and $\mathbf{C}$ is the matrix of accumulative friction and damping. The superscripts $R$ and $L$ represent right and left sides of an element. After applying the boundary conditions, the rank of the system transfer matrix $\mathbf{T}$ is reduced, which forms a new matrix (TT). All matrices are involved with the variable $\omega$ (angular frequency). The natural frequency $(f=\omega /(2 \pi))$ of the system can be found when the determinant of the matrix is equal to zero. The mode shape of a certain frequency is obtained by substituting the frequency back into the equation. Figure 2 describes the algorithm used for obtaining the required results.

Figure 2 Flow chart of result searching algorithm

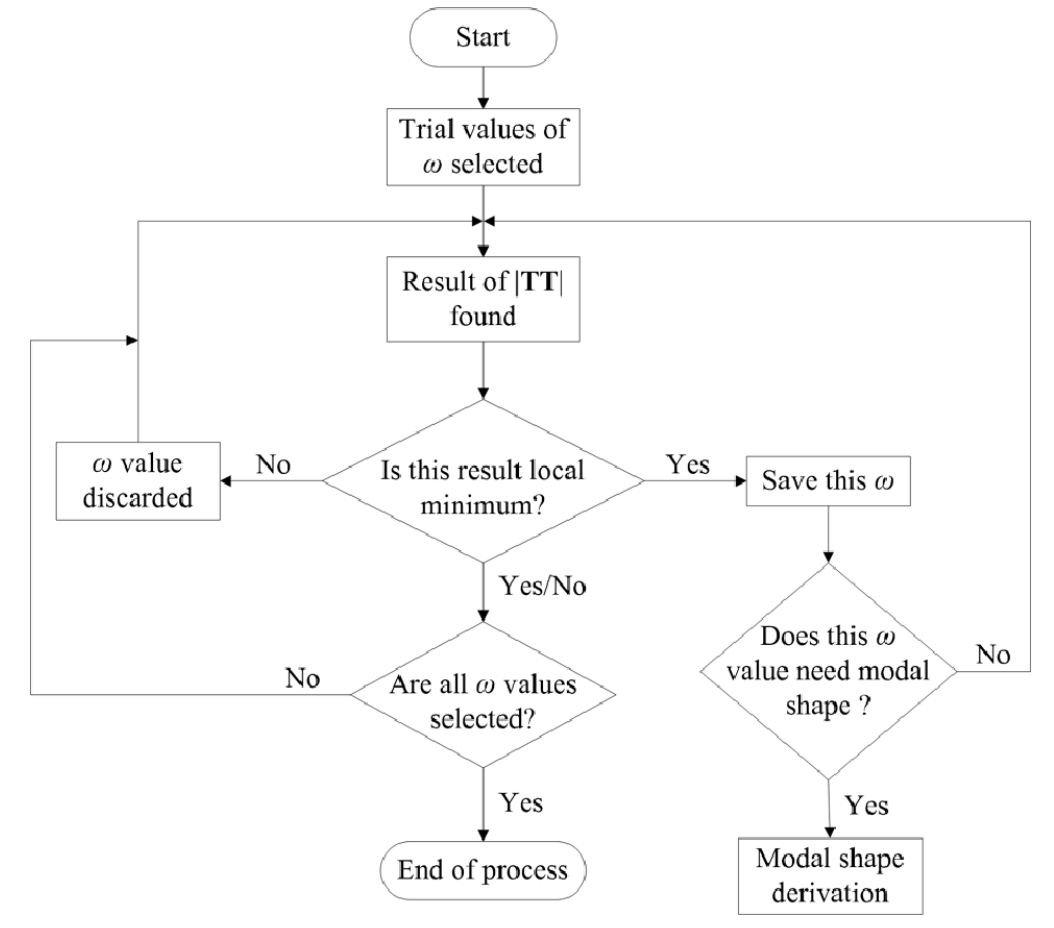

\section{Experiment and validation of the developed model}

\subsection{Test configuration}

Figure 3 is a schematic diagram of the hydraulic circuit fixed on a test rig. The circuit consists of a double acting hydraulic cylinder located on the left side, two nitrogen-filled diaphragm-type hydraulic accumulators on each line, a pressure gauge in the middle branch, two kinds of isolating valves, several pressure transducers, hydraulic hoses, and steel pipes. The experiments are performed on the upper line, and the lower line serves to settle the test conditions of the upper line.

The experiments involve two types of piping systems: one is a straight pipeline (referred to here as System 1), and the other is an L-shaped pipeline (referred to here as 
System 2). Both systems consist of pipes, pressure transducers, accelerometers, a hose and an accumulator. The experimental lines are fixed on the test rig by supports. The circuits are filled with hydraulic oil and the upper lines are separated from the lower ones by isolating valves that are completely hermetic. The phenomenon of pipeline cavitations is not considered in this study, so air bubbles are removed before the experiments and the circuit is sealed and pressurised.

The schematic diagram of the piping system is shown in Figure 3 and the photos of the two pipelines are shown in Figure 4. The experimental parameters are listed in Table 1.

Figure 3 Schematic diagram of the hydraulic circuit

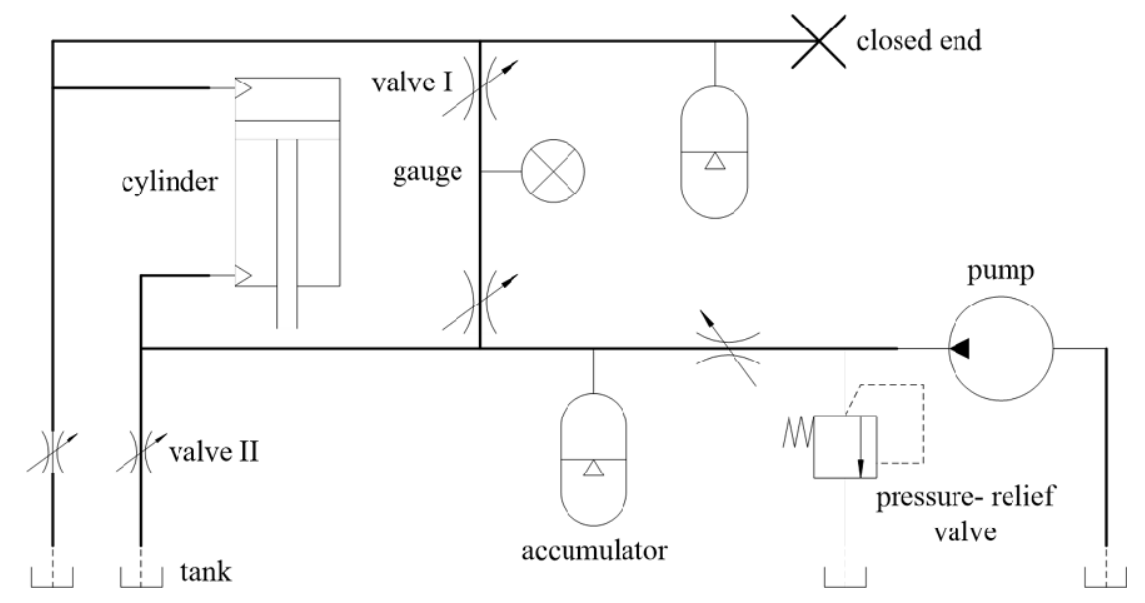

Table 1 Physical properties of experiment

\begin{tabular}{|c|c|c|c|}
\hline Property & Value & Property & Value \\
\hline \multicolumn{2}{|c|}{ Pipe } & \multicolumn{2}{|c|}{ Hose } \\
\hline Inner diameter & $0.0165(\mathrm{~m})$ & Inside diameter $\left(r_{i}\right)$ & $0.0127(\mathrm{~m})$ \\
\hline Wall thickness & $0.0012(\mathrm{~m})$ & Outside diameter $\left(r_{o}\right)$ & $0.0208(\mathrm{~m})$ \\
\hline Density & $7850\left(\mathrm{~kg} / \mathrm{m}^{3}\right)$ & Density & $1.5 \times 10^{3}\left(\mathrm{~kg} / \mathrm{m}^{3}\right)$ \\
\hline Young's modulus & $207(\mathrm{GPa})$ & Axial Young's modulus & $1.5(\mathrm{GPa})$ \\
\hline Shear modulus & $79.3(\mathrm{GPa})$ & Shear modulus & $3.5(\mathrm{GPa})$ \\
\hline Poisson's ratio & 0.3 & Poisson's ratio & 0.35 \\
\hline \multicolumn{2}{|c|}{ Oil } & \multicolumn{2}{|c|}{ Accumulator } \\
\hline Density & $870\left(\mathrm{~kg} / \mathrm{m}^{3}\right)$ & Weight & $1.8076(\mathrm{~kg})$ \\
\hline Bulk modulus & $1400(\mathrm{MPa})$ & Pre-pressure & $0.2(\mathrm{MPa})$ \\
\hline Viscosity & $0.05\left(\mathrm{~N} \mathrm{~s} / \mathrm{m}^{2}\right)$ & Pre-volume & $0.32(\mathrm{~L})$ \\
\hline
\end{tabular}

\subsection{Experimental data acquisition}

A diagram of the test rig data acquisition arrangement is shown in Figure 5. The data recorded are the input force signal (either hammer or shaker force), the response pressure and acceleration signals. The signals from the transducers are sent to a PC that is 
equipped with an NI data acquisition module (model NI cDAQ-9178) and LabVIEW. The force and acceleration signals go through separate amplifiers before they reach the module. The NI software, installed in the PC, graphically displays both time and frequency domain information and allows the user to examine the data before saving it. The measured data is then processed to provide the required information for subsequent analysis.

Figure 4 Configurations of test rigs: (a) frequency test of System 1 and (b) mode shape test of System 2 (see online version for colours)
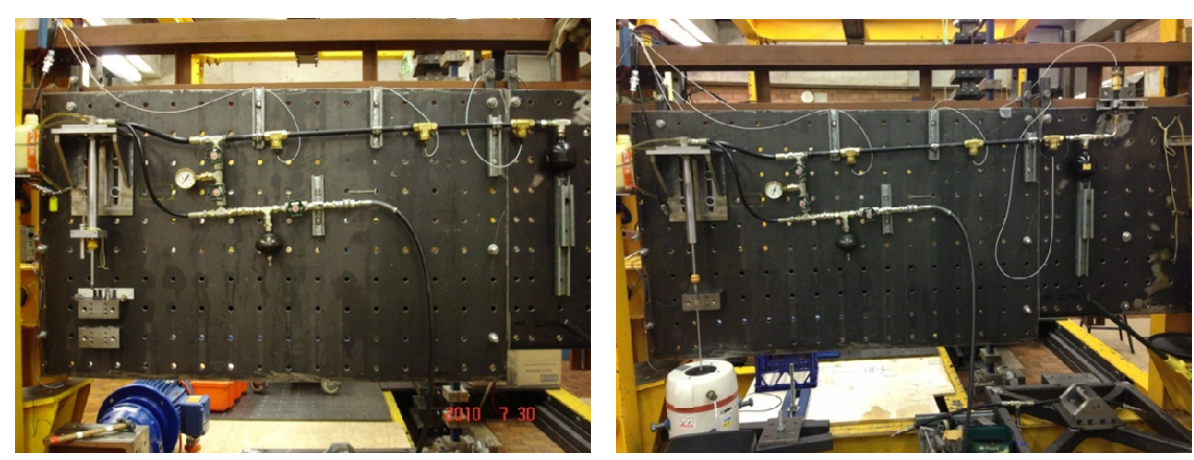

Figure 5 Flow chart of test rig data acquisition (see online version for colours)

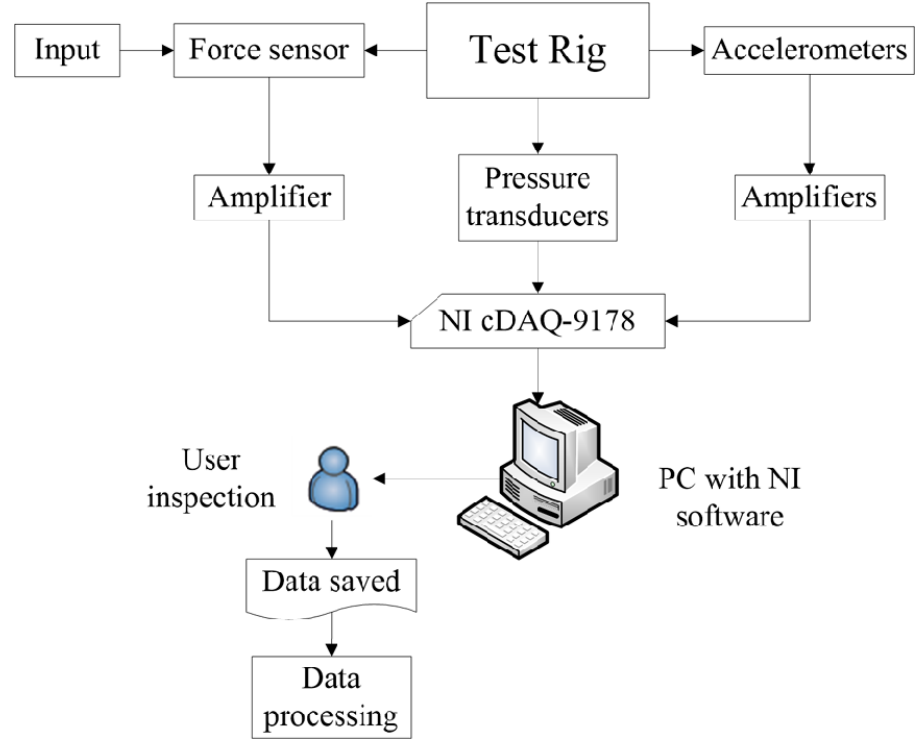

\subsection{Comparison of results}

\subsubsection{Frequency comparison}

The simulation and experimental results of two systems are compared in Tables 2 and 3. Generally speaking, the results match well with each other. Numerical simulation results give some lower frequencies which cannot be found experimentally. 
These frequencies are most likely from the structural modes that are measured by accelerometers. Some low frequencies might be mixed with ambient noise and missed by the accelerometer owing to the sensitivity limit.

Table 2 Simulation and test frequencies of System 1

\begin{tabular}{|c|c|c|c|c|c|c|c|c|c|c|}
\hline Frequency $(\mathrm{Hz})$ & & $f_{l}$ & & & $f_{2}$ & $f_{3}$ & $f_{4}$ & $f_{5}$ & $f_{6}$ & $f_{7}$ \\
\hline Simulation results & 24.5 & 37.2 & 50.5 & 73.2 & 97.7 & 132.3 & 163.8 & 253.5 & 277.7 & 295.7 \\
\hline Test results & & 37 & & & 95 & 132 & 164 & 254 & 277 & 296 \\
\hline
\end{tabular}

Table 3 Simulation and test frequencies of System 2

\begin{tabular}{|c|c|c|c|c|c|c|c|c|c|c|c|}
\hline Frequency $(\mathrm{Hz})$ & & $f_{1}$ & & $f_{2}$ & $f_{3}$ & $f_{4}$ & $f_{5}$ & $f_{6}$ & $f_{7}$ & $f_{8}$ & $f_{9}$ \\
\hline Simulation results & 22.6 & 35.2 & 69.7 & 100.3 & 118.4 & 126.2 & 156.9 & 237.8 & 248.8 & 272.8 & 298.6 \\
\hline Test results & & 35 & & 100 & 114 & 128 & 157 & 237.5 & 249 & 268 & 298 \\
\hline
\end{tabular}

The axial mode frequencies measured by pressure transducers are mainly influenced by fluid dynamics. The frequencies measured by the accelerometers are lateral mode frequencies, which are mostly affected by structural dynamics. Some frequencies are measured by both types of transducers, indicating that these are fluid-structure coupling frequencies.

\subsubsection{Mode shape comparison}

Figure 6 illustrates the mode shapes of the coupling frequencies for System 1. The simulation mode shapes of the lateral force are compared with the measured ones. The measured pressure mode shapes of the whole pipeline could not be obtained due to the limited measurement locations. There are three pressure transducers incorporated along the pipeline, so the pressure signals on three points can be acquired and compared.

Figure 6 Mode shapes of System 1: (a) lateral force at $132 \mathrm{~Hz}$; (b) pressure at $132 \mathrm{~Hz}$; (c) lateral force at $164 \mathrm{~Hz}$; (d) pressure at $164 \mathrm{~Hz}$; (e) lateral force at $296 \mathrm{~Hz}$ and (f) pressure at $296 \mathrm{~Hz}$

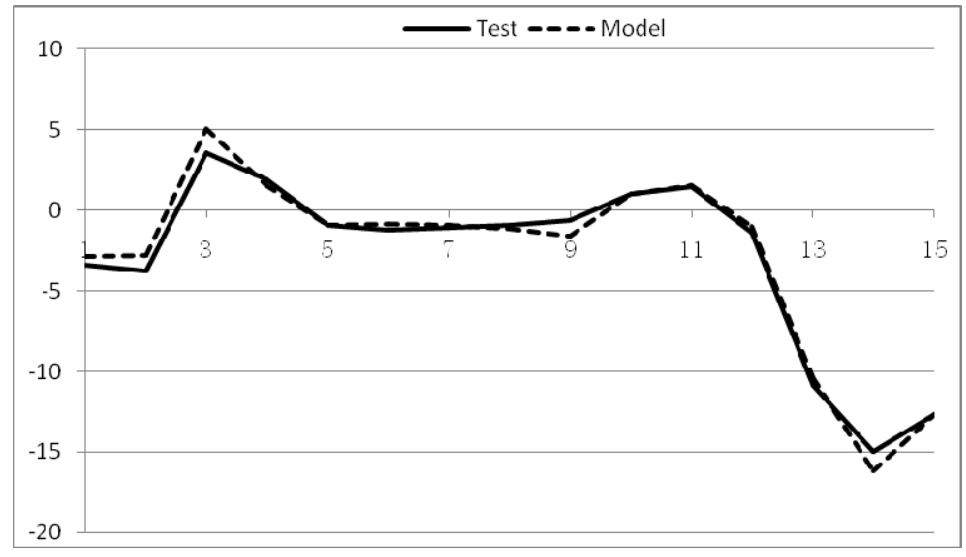

(a) 
Figure 6 Mode shapes of System 1: (a) lateral force at $132 \mathrm{~Hz}$; (b) pressure at $132 \mathrm{~Hz}$; (c) lateral force at $164 \mathrm{~Hz}$; (d) pressure at $164 \mathrm{~Hz}$; (e) lateral force at $296 \mathrm{~Hz}$ and (f) pressure at $296 \mathrm{~Hz}$ (continued)

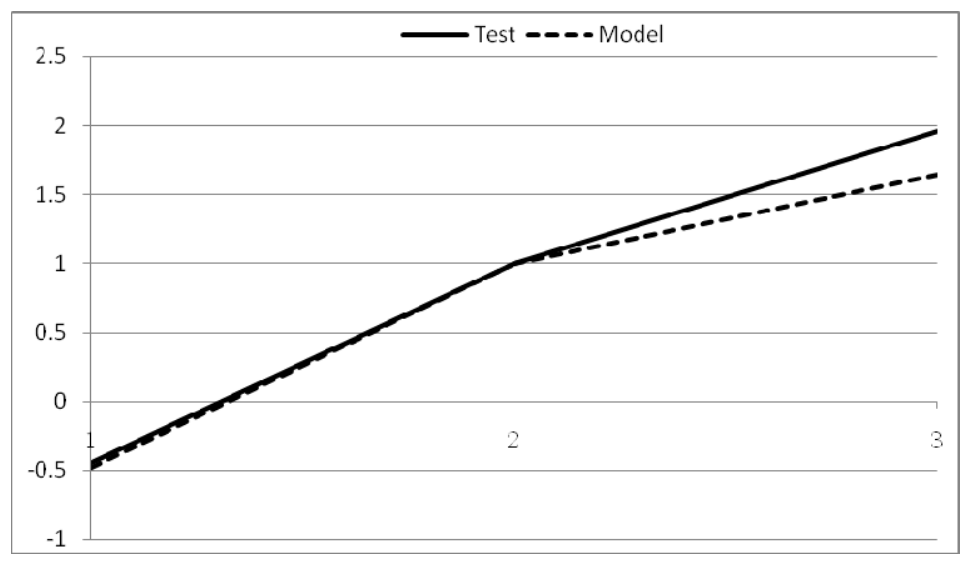

(b)

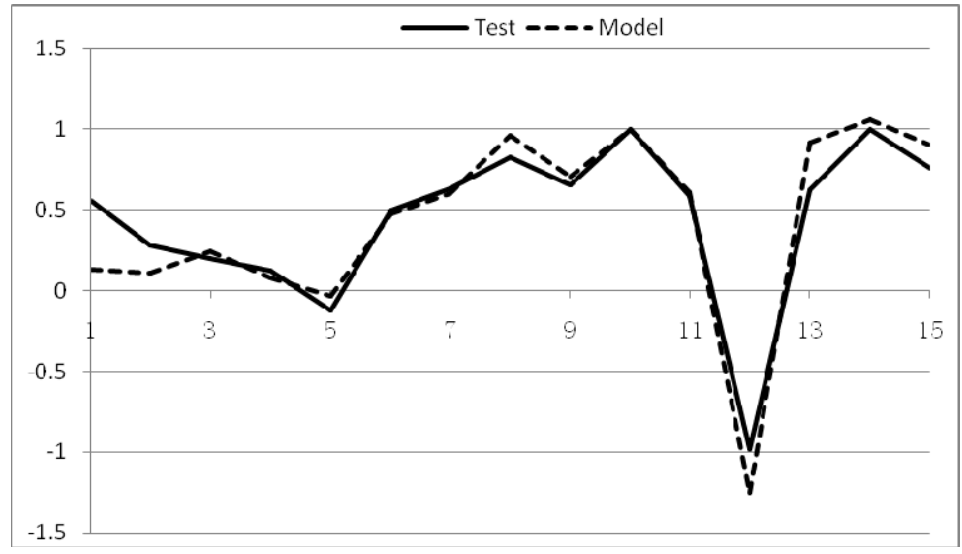

(c)

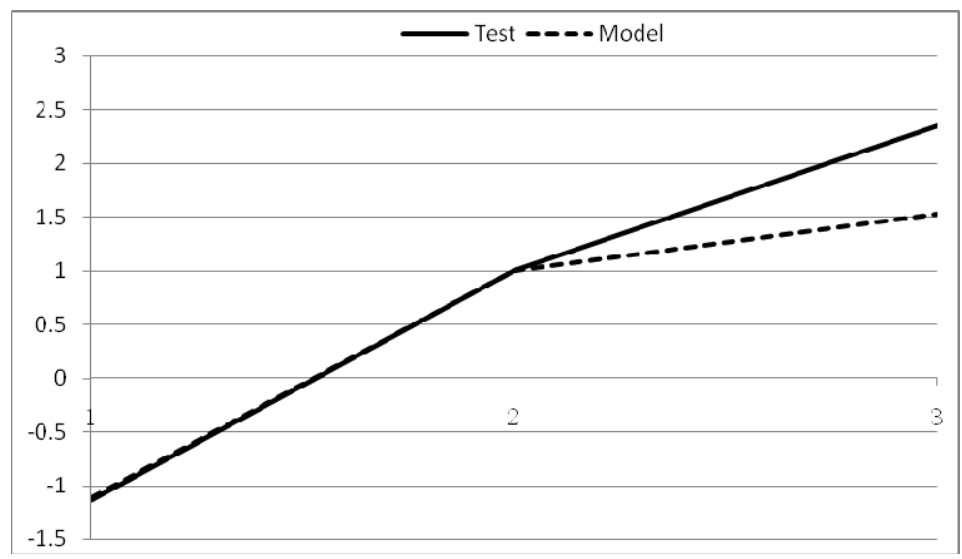

(d) 
Figure 6 Mode shapes of System 1: (a) lateral force at $132 \mathrm{~Hz}$; (b) pressure at $132 \mathrm{~Hz}$; (c) lateral force at $164 \mathrm{~Hz}$; (d) pressure at $164 \mathrm{~Hz}$; (e) lateral force at $296 \mathrm{~Hz}$ and (f) pressure at $296 \mathrm{~Hz}$ (continued)

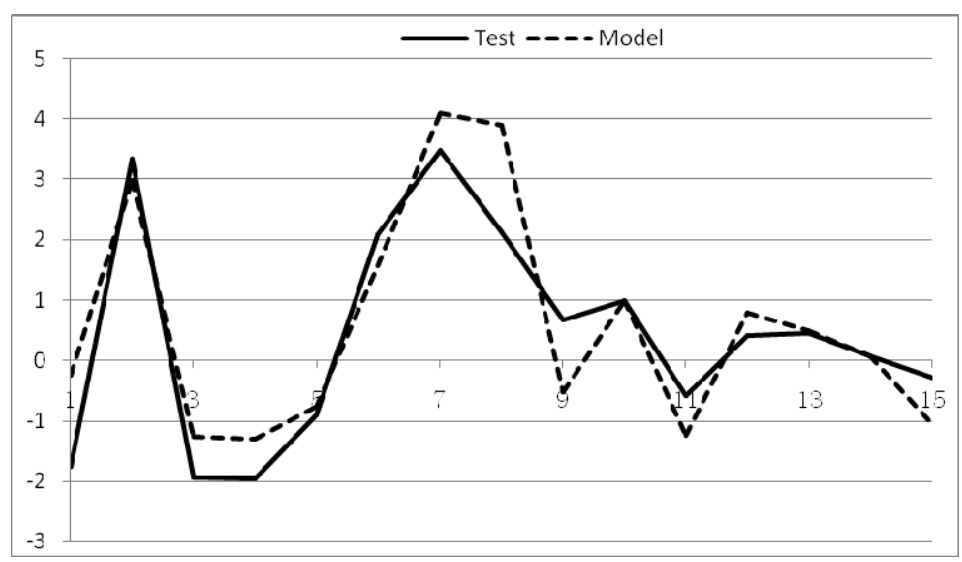

(e)

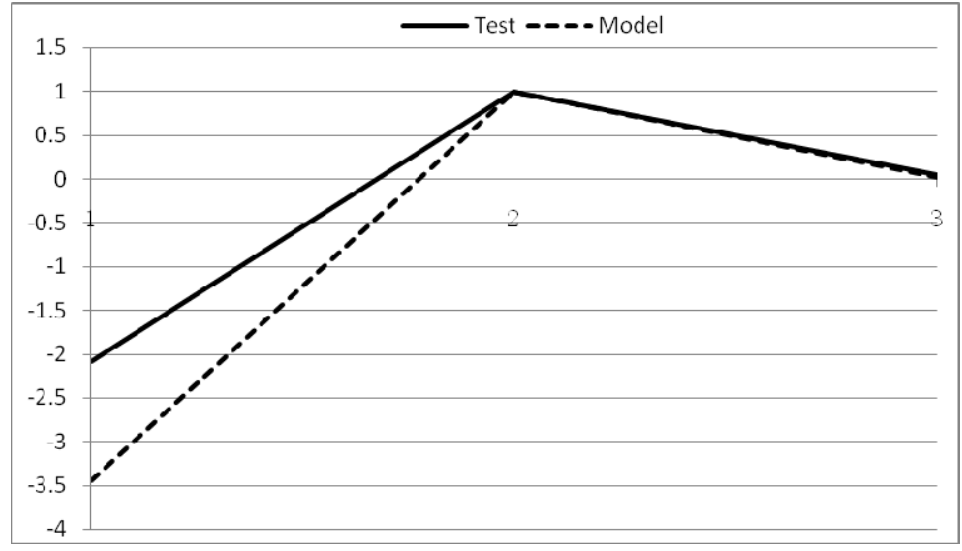

(f)

From Figure 6, it can be concluded that the mode shapes of the simulation model and experimental results are essentially matched. The deviations of pressure modes could result from the simplification of the actual fluid. For example, the obvious difference in the two mode shapes of the lateral force at $296 \mathrm{~Hz}$ may be from imprecise measuring, calculation limitation and possible air bubbles in the test system.

Figure 7 illustrates the mode shapes of three natural frequencies for System 2. Again for the pressure measurement, there is not enough information acquired to derive the mode shapes of the whole pipeline because only four pressure transducers are installed in this system. Accordingly, the pressure relationship at these four points is shown in this figure. 
Figure 7 Mode shapes of System 2: (a) lateral force at $126 \mathrm{~Hz}$; (b) pressure at $126 \mathrm{~Hz}$; (c) lateral force at $157 \mathrm{~Hz}$; (d) pressure at $157 \mathrm{~Hz}$; (e) lateral force at $298 \mathrm{~Hz}$ and (f) pressure at $298 \mathrm{~Hz}$

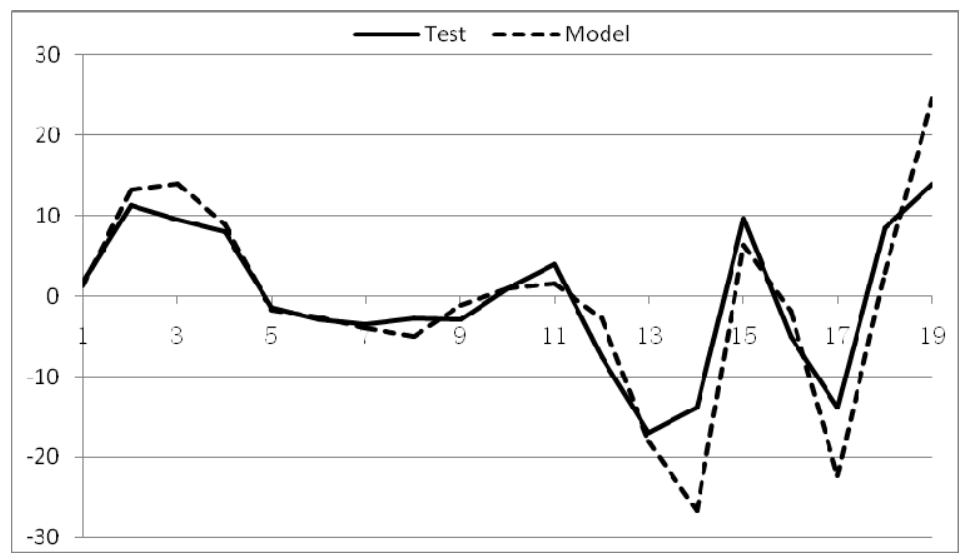

(a)

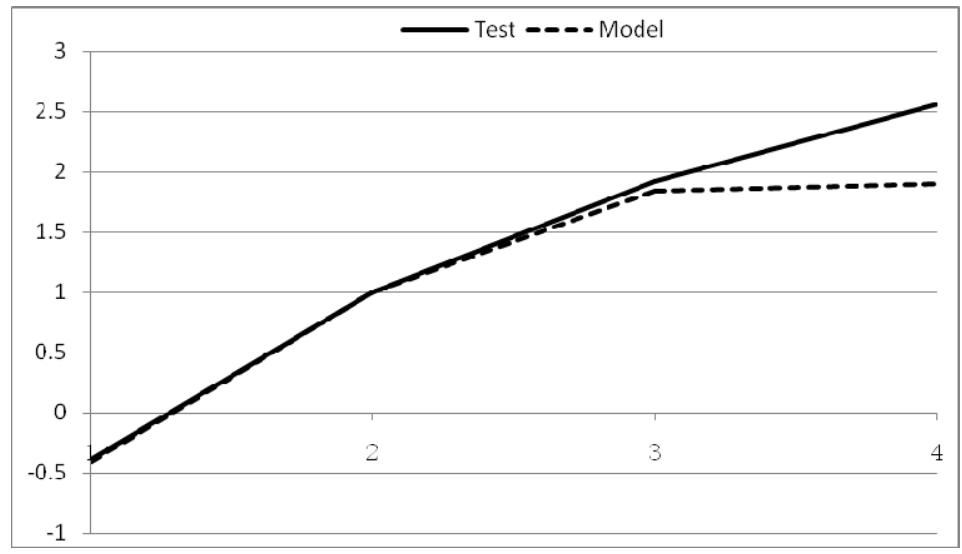

(b)

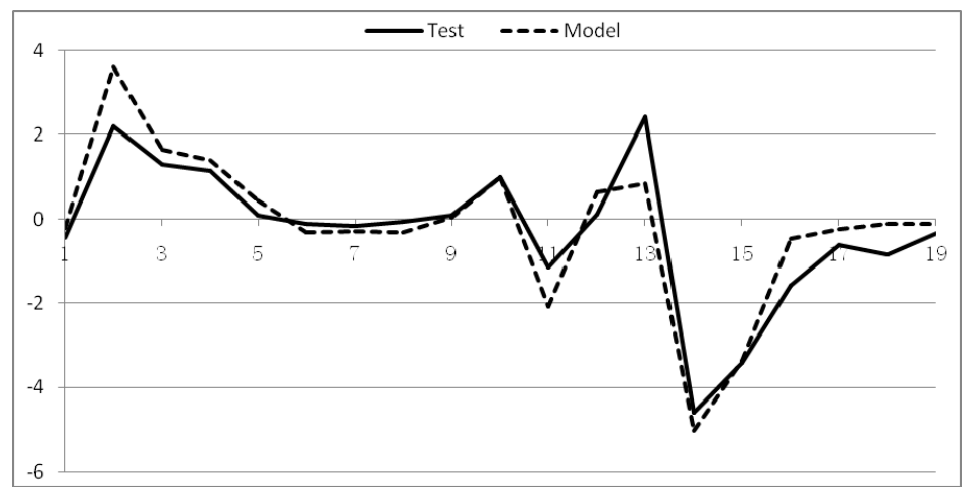

(c) 
Figure 7 Mode shapes of System 2: (a) lateral force at $126 \mathrm{~Hz}$; (b) pressure at $126 \mathrm{~Hz}$; (c) lateral force at $157 \mathrm{~Hz}$; (d) pressure at $157 \mathrm{~Hz}$; (e) lateral force at $298 \mathrm{~Hz}$ and (f) pressure at $298 \mathrm{~Hz}$ (continued)

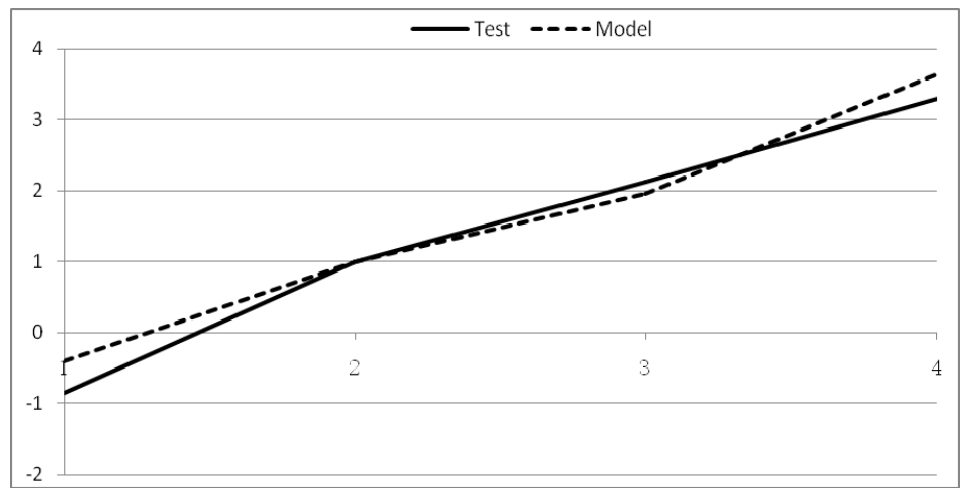

(d)

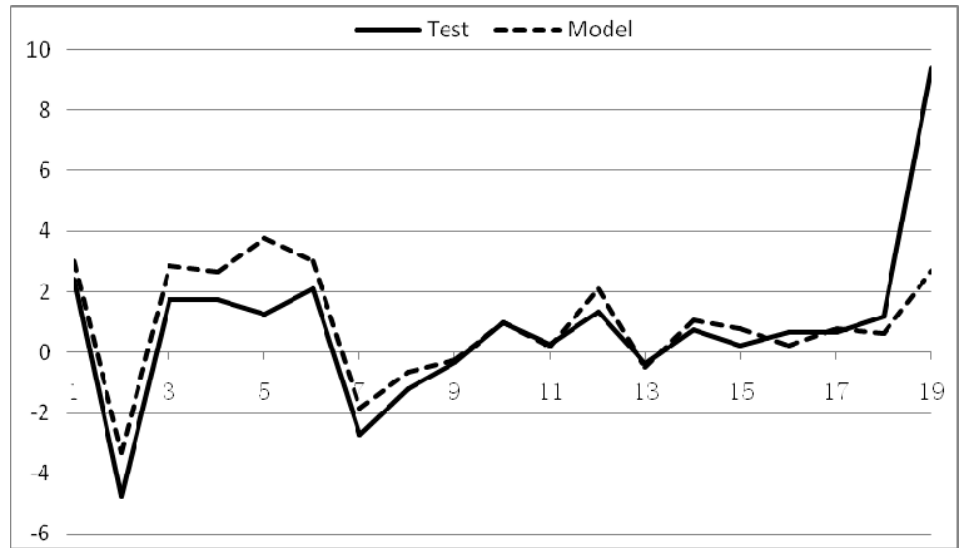

(e)

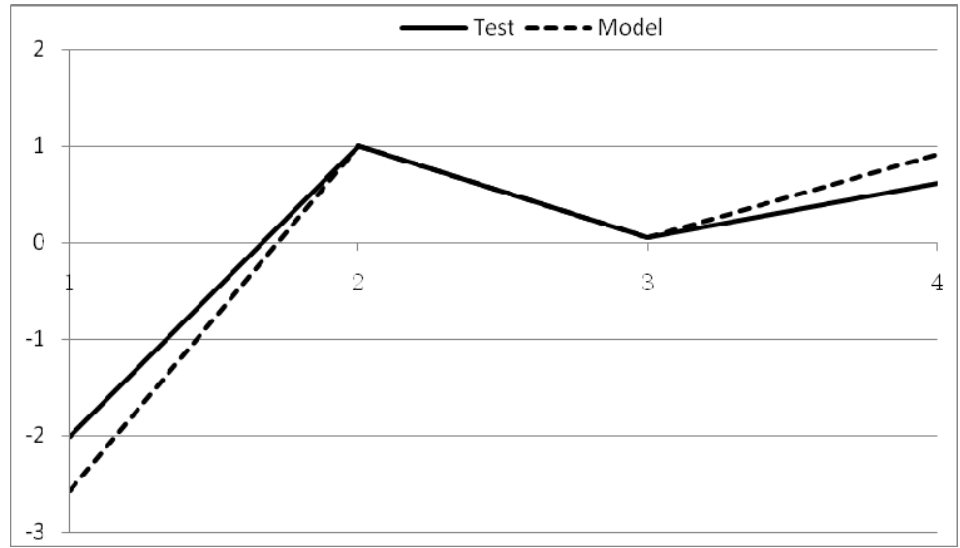

(f) 
The assumption of very small pressure inputs can lead to incorrect results in the calculations of mode shape. The input pressure at the left end of the system was not measured (as a matter of fact, it is not necessary to measure it). Applying an assumed value, the required mode shapes can be obtained using MATLAB codes. In order to conveniently compare the simulation and test results, the data are normalised. All the pressure data are divided by the data from one location, where the second pressure transducer is equipped and a reference accelerometer is located.

These are some sources of discrepancy between the experimental results and simulation results. Experimental data is influenced by many factors. For example, the frequency range of the background noise may cover some low structural frequencies, thus the lower natural frequencies may not be identified. The measured mode shape involves the mobile accelerometer that is moved manually. The acquired data depends on the position, orientation and monitoring of the accelerometer, thus the human factor may affect the measurements. The system is assumed to be a liquid-filled pipeline without air bubbles, but residual air in the system is very difficult to eliminate. On the other hand, the simulation model usually simplifies the actual system. The cylinder end is considered as the fixed and close end, but actually it is more complex. Although the circuits connected to the top and bottom chambers are separated by valves, an accumulator installed in the lower circuit allows for possible fluid movement in the system when the experiments are performed. In addition, the cylinder is not really a rigid body, so the simplified boundary conditions may affect the simulation results. The liquid of the experiments is assumed to be incompressible, which could also affect the simulation results.

\section{Effects of the piping system on axial system dynamics (simulation analysis)}

\subsection{Hose influence}

The hose has significant effects on axial system dynamics. Taking the System 1 as an example, Figures 8-10 show that the influence of hose length, elastic moduli, and density on the axial system natural frequencies respectively. These figures indicate that the effects are more obvious in the middle and high frequency ranges.

According to Figure 8, the longer the hose, the lower the system natural frequencies. Since the longer hose decreases the system stiffness, the natural frequencies of the 'softer' system are lower than the original ones. Figure 9 indicates that the increasing stiffness of hoses leads to the increase of the system natural frequencies. As shown in Figure 10, the hose density has almost no impact on the axial system natural frequencies.

From these three figures, it can be concluded that the length and elastic moduli of the hose have more impact than the density on system natural frequencies. For the straight pipeline, the axial frequencies are influenced by the hose wall with the Poisson coupling, which is mainly determined by the elasticity of the hose wall (the moduli of the hose wall). Hoses can be considered as soft pipes, so the length of the hose in a system affects the elastic moduli of the whole pipeline. Therefore, the hose length also shows obvious effects on the system natural frequencies. 
Figure 8 Effect of hose length

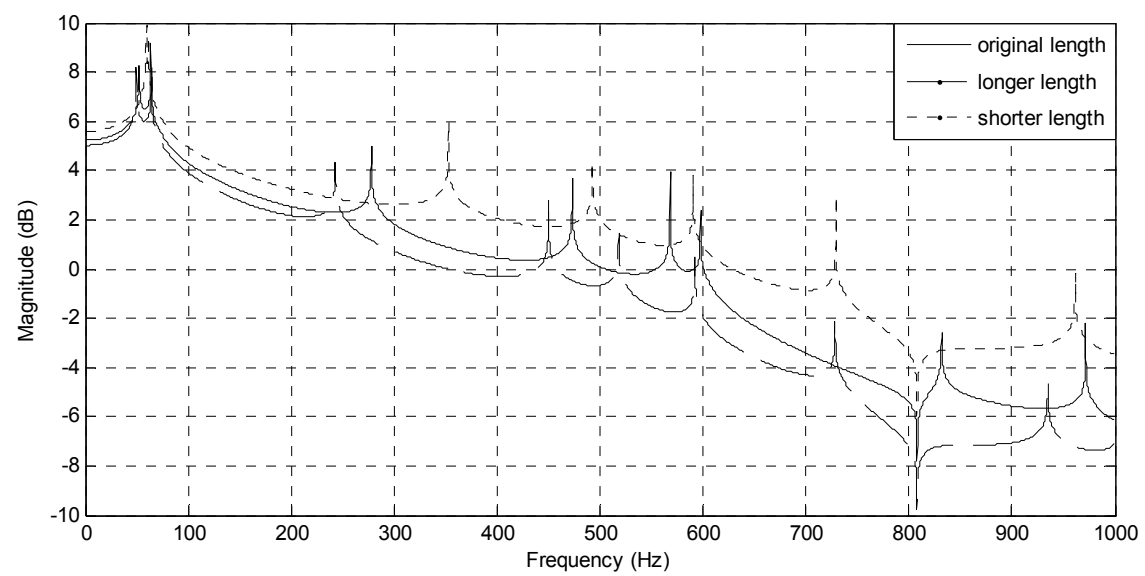

Figure 9 Effect of hose elastic moduli

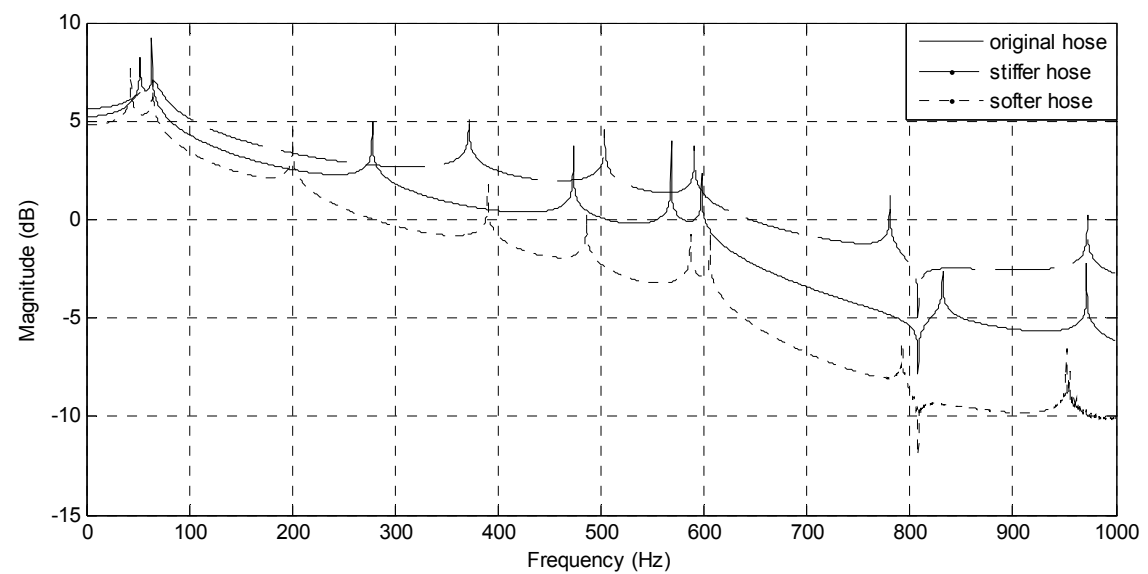

Figure 10 Effect of hose density

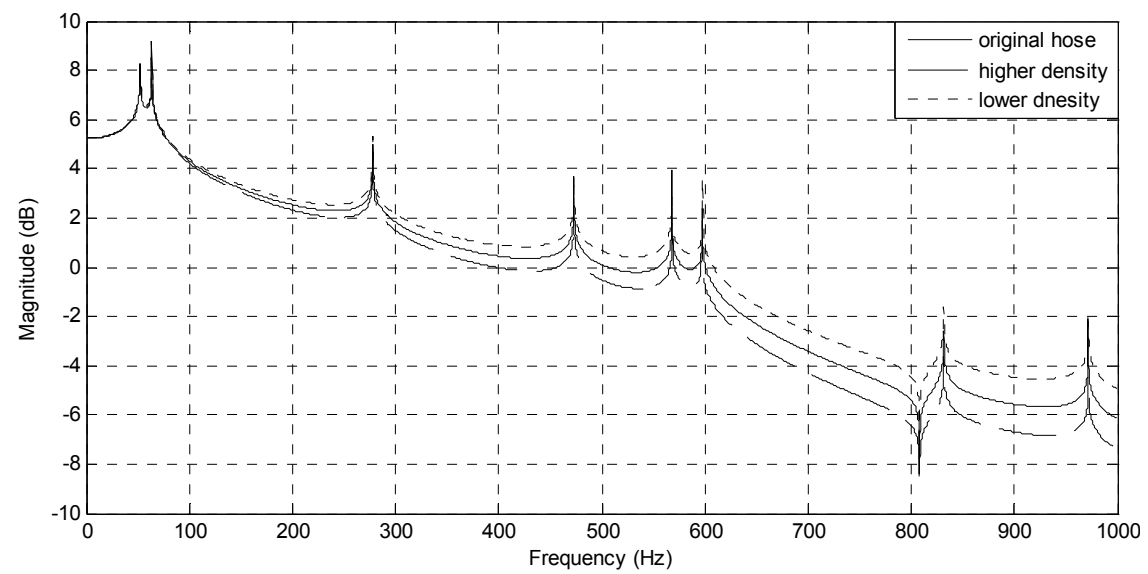




\subsection{Pipe influence}

The inner diameter of the pipeline has an impact on the axial system natural frequencies, as shown in Figure 11. The larger diameter of the pipeline gives a higher stiffness for the system, thus the natural frequencies shift upwards.

Figure 11 Effect of pipeline inner diameter

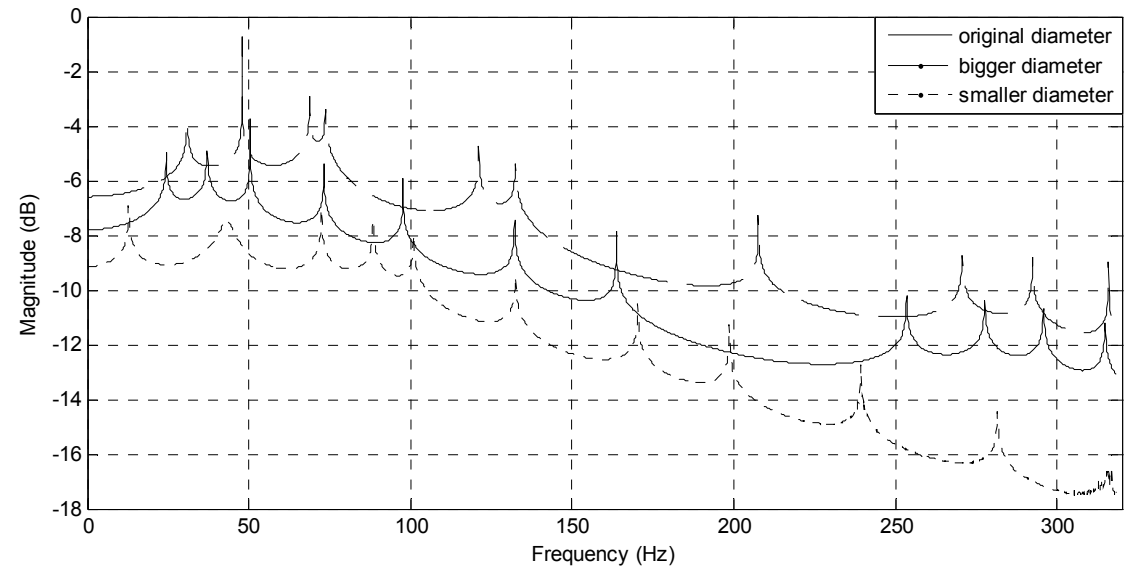

Figure 12 shows the effects of pipe wall thickness on system natural frequencies. According to the simulation results, the thicker the pipe wall, the higher the system natural frequencies. This is because the increased thickness of the pipe wall provides additional stiffness to the system, consequently increasing the natural frequencies.

Figure 12 Effect of pipe wall thickness

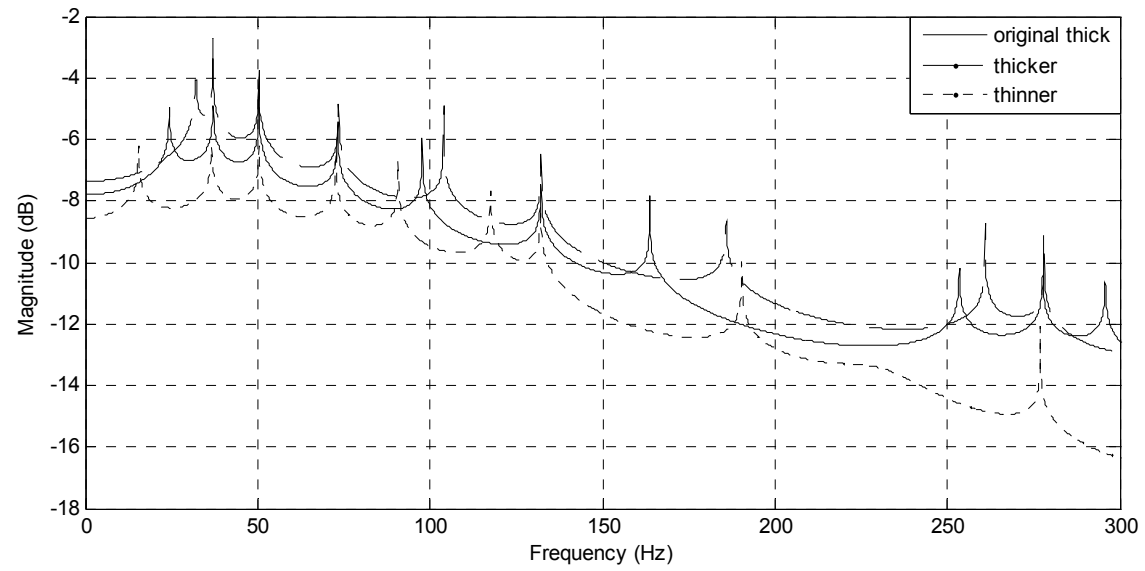

Table 4 and Figure 13 show that the system natural frequencies increase with an increased pipe elastic modulus. The major impact is on three frequencies $\left(f_{7}, f_{8}, f_{10}\right)$ as these frequencies are influenced by both the fluid and structure. The elastic modulus has significant effects on the Poisson coupling, and in turn it affects the fluid dynamics in the axial direction. 
Table 4 Effect of pipe elastic modulus

\begin{tabular}{lcccccccccc}
\hline Frequency $(\mathrm{Hz})$ & $f_{1}$ & $f_{2}$ & $f_{3}$ & $f_{4}$ & $f_{5}$ & $f_{6}$ & $f_{7}$ & $f_{8}$ & $f_{9}$ & $f_{10}$ \\
\hline$E=250 \mathrm{GPa}$ & 26.6 & 37.2 & 50.5 & 73.4 & 100.1 & 132.3 & 173.6 & 264.2 & 277.9 & 310.2 \\
Original model & 24.5 & 37.2 & 50.5 & 73.2 & 97.7 & 132.3 & 163.8 & 253.5 & 277.7 & 295.7 \\
$E=207 \mathrm{GPa}$ & & & & & & & & & & \\
$E=160 \mathrm{GPa}$ & 21.6 & 36.9 & 50.5 & 73.1 & 94.7 & 132.1 & 148.7 & 233.8 & 272.5 & 293.2 \\
\hline
\end{tabular}

Figure 13 Effect of pipe elastic modulus

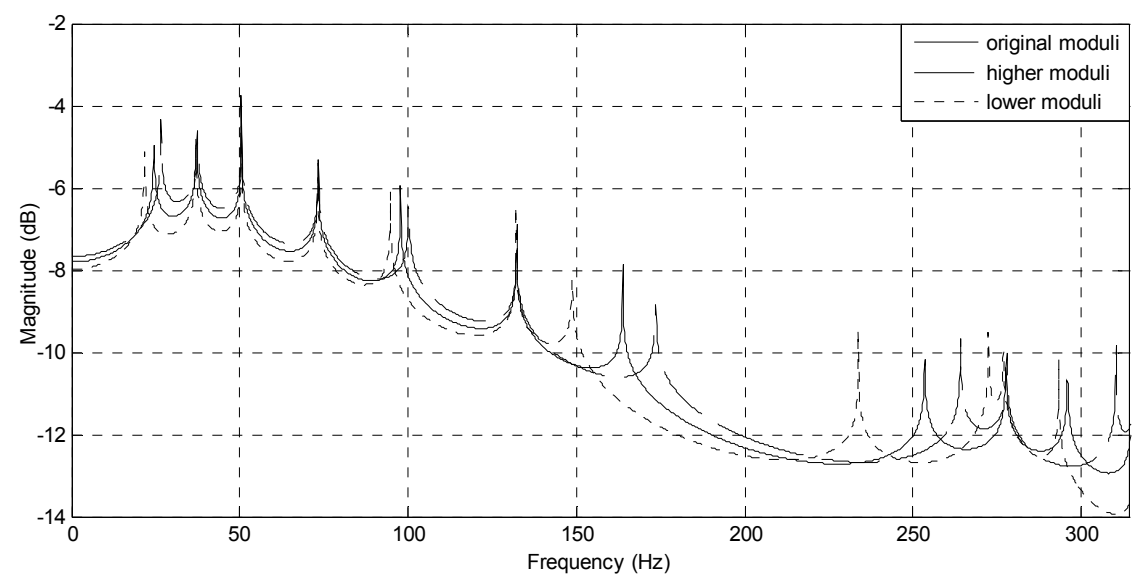

As demonstrated in Figure 14, the influence of pipe density on system natural frequencies increases with the frequency value, leaving the lower frequencies unchanged. This implies that density could be used to modify the system parameters to reduce audible noise.

Table 5 uses two frequencies $(277.7 \mathrm{~Hz}$ and $163.8 \mathrm{~Hz})$ to quantitatively exhibit the influence of hose and pipe properties.

Figure 14 Effect of pipe density

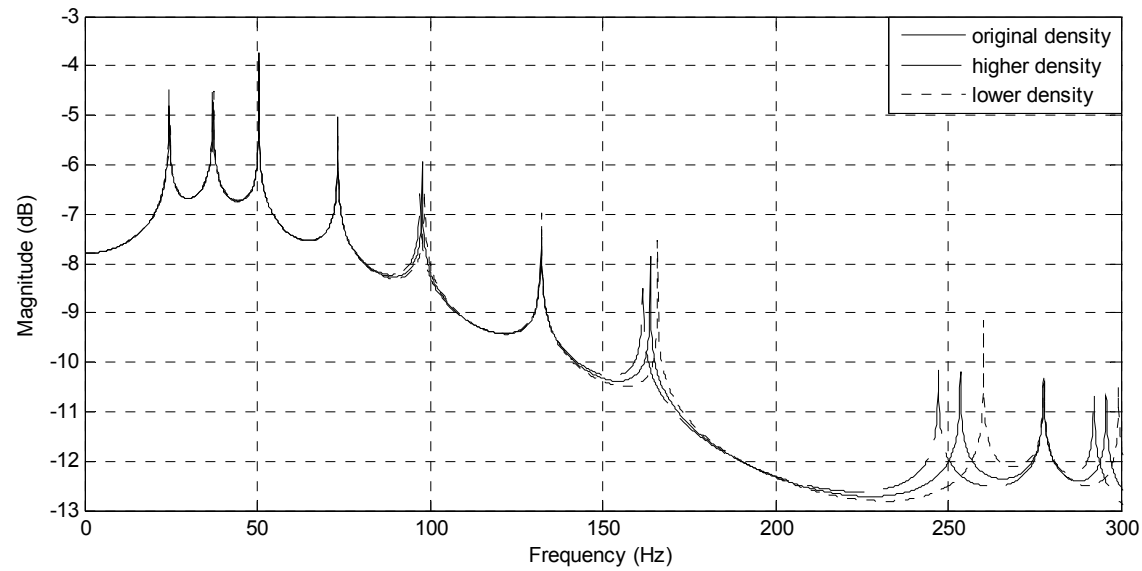


Table 5 Quantitative comparison

\begin{tabular}{lccccc}
\hline & $\begin{array}{c}\text { Frequency } \\
\text { of original } \\
\text { value }(\mathrm{Hz})\end{array}$ & $\begin{array}{c}\text { Frequency } \\
\text { of higher value } \\
(\mathrm{Hz})\end{array}$ & $\begin{array}{c}\text { Magnitude } \\
\text { change }\end{array}$ & $\begin{array}{c}\text { Frequency } \\
\text { of lower } \\
\text { value }(\mathrm{Hz})\end{array}$ & $\begin{array}{c}\text { Magnitude } \\
\text { change }\end{array}$ \\
\hline Length & 277.7 & 242.9 & $12.5 \%$ & 352.7 & $27.0 \%$ \\
Elastic moduli & 277.7 & 371.6 & $33.8 \%$ & 200.4 & $27.8 \%$ \\
Density & 277.7 & 277.7 & 0 & 277.7 & 0 \\
Pipe property & & & & & \\
Diameter & 163.8 & 207.7 & $26.8 \%$ & 170.3 & $4.0 \%$ \\
Thickness & 163.8 & 185.9 & $13.5 \%$ & 190.5 & $16.3 \%$ \\
Elastic modulus & 163.8 & 173.6 & $6.0 \%$ & 148.7 & $9.2 \%$ \\
Density & 163.8 & 161.5 & $1.4 \%$ & 166.0 & $1.3 \%$ \\
\hline
\end{tabular}

\section{Conclusion}

This paper developed an extended TMM model for free vibration analysis of a liquidfilled pipe system and presented the experimental validation of the model. The system model includes field matrices for pipe and hose sections, and point matrices for structural components including concentrated masses, spring supports and elbows and for fluidic discontinuities such as damper valves and accumulators. The comparison between experimental and simulation results shows that the theoretical model can properly describe the FSI piping system and the correlation between them is reasonably good. The factors contributing to this deviation are explained from both experimental and simulation viewpoints.

It was found that the system steady-state characteristics can be modified by changing the component properties. Both the material and dimension of hoses and pipes affect system dynamics, especially in the middle and high frequencies (the source of audible noises). The developed model of the piping system can be employed to analyse the system steady-state dynamics, however for transient dynamics, further research work is needed. The developed model in this paper adopts the TMM. When it is coupled with other structures, the model could be represented by different types of mathematical models (e.g., finite element method). The methodology of how to combine the various mathematical models will be the focus of further research. In addition, further application of the extended models is also important.

\section{Acknowledgement}

The authors would like to thank two anonymous reviewers for their helpful suggestions and comments, on which the quality of this paper has been improved. The authors would also like to thank Mr. Chris Chapman for his help with experiments and proofreading. 


\section{References}

Drew, J.E., Longmore, D.K. and Johnston, D.N. (1997) 'Measurement of the longitudinal transmission characteristics of fluid-filled hoses', Proceedings of the Institution of Mechanical Engineers, Part I: Journal of Systems and Control Engineering, Vol. 211, No. 3, pp.219-228.

Edge, K.A. and Johnston, D.N. (1991) 'The impedance characteristics of fluid power components: relief valves and accumulators', Proc IMechE, Part I: Journal of Systems and Control Engineering, Vol. 205, pp.11-22.

Evans, J.J. and Wilcox, P.D. (2002) 'A structural model for high pressure helical wire-wound thermoplastic hose', International Journal of Solids and Structures, Vol. 39, No. 5, pp.1307-1326.

Fontdecaba, i. and Buj, J. (2002) Integral Suspension System for Motor Vehicles based on Passive Components, SAE Technical Paper Series, SAE 2002-01-3105.

Iijima, T., Akatsu, Y., Takahaski, K. and Murakami, H. (1993) Development of a Hydraulic Active Suspension, SAE Technical Paper Series, SAE 931971.

Johnston, D.N. and Edge, K.A. (1989) 'Simulation of the pressure ripple characteristics of hydraulic circuits', Proceedings of the Institution of Mechanical Engineers, Part C: Journal of Mechanical Engineering Science, Vol. 203, No. C4, pp.275-282.

Johnston, D.N. and Edge, K.A. (1991) 'The impedance characteristics of fluid power components: restrictor and flow control valves', Proc IMechE, Part I: Journal of Systems and Control Engineering, Vol. 205, pp.3-10.

Johnston, D.N., Tim, M.W. and Kerry, M.C. (2007) 'Measurement of wave propagation characteristics of flexible hoses', ASME 2007 International Mechanical Engineering Congress and Exposition (IMECE2007), ASME, Seattle, Washington, USA, pp.159-167.

Liu, P.J., Rakheja, S. and Ahmed, A.K.W. (1995a) 'Analytical study of an interconnected vehicle suspension', Proceedings of the 1995 ASME International Mechanical Engineering Congress and Exposition, San Francisco, USA, pp.151-160.

Liu, P.J., Rakheja, S. and Ahmed, A.K.W. (1995b) 'Properties of an interconnected hydropneumatic suspension system', Transactions of the Canadian Society for Mechanical Engineering, Vol. 19, No. 4, pp.383-396.

Longmore, D.K., Johnston, D.N. and Drew, J.E. (1997) 'Measurement of the dynamic properties of hose walls required for modelling fluid-borne noise', Proceedings of the 1997 ASME International Mechanical Engineering Congress and Exposition, The Fluid Power and Systems Technology Division (Publication) FPST, Dallas, TX, USA, pp.105-111.

Longmore, D.K. and Schlesinger, A. (1991a) 'Transmission of vibration and pressure fluctuations through hydraulic hoses', Proceedings of the Institution of Mechanical Engineers, Part I: Journal of Systems and Control Engineering, Vol. 205, No. I2, pp.94-104.

Longmore, D.K. and Schlesinger, A. (1991b) 'Relative importance of the various vibration transmitting mechanisms in hoses in typical hydraulic systems', Proceedings of the Institution of Mechanical Engineers, Part I: Journal of Systems and Control Engineering, Vol. 205, No. I2, pp.105-111.

Mace, N. (2004) Analysis and Synthesis of Passive Interconnected Vehicle Suspensions, University of Cambridge, Cambridge, UK.

Mavroudakis, B. and Eberhard, P. (2006) 'Mode decoupling in vehicle suspensions applied to race cars', III European Conference on Computational Mechanics: Solids, Structures and Coupled Problems in Engineering, Lisbon, Portugal.

Mrad, R.B., Levitt, J.A. and Fassois, S.D. (1994) 'Non-linear dynamic modeling of an automobile hydraulic active suspension system', Mechanical Systems and Signal Processing, Vol. 8, No. 5, pp.485-517.

Ortiz, M. (1997) 'Principles of interconnected suspension', RaceCar Engineering, pp.56-59, 76-81. 
Prek, M. (2007) 'Analysis of wave propagation in fluid-filled viscoelastic pipes', Mechanical Systems and Signal Processing, Vol. 21, No. 4, pp.1907-1916.

Qatu, M., Llewellyn, D. and Edwards, R. (2000) Correlation of Hydraulic Circuit Dynamic Simulation and Vehicle, SAE Technical Paper Series, SAE 2000-01-0811: pp.103-112.

Rideout, G. and Anderson, R.J. (2003) 'Experimental testing and mathematical modeling of the interconnected Hydragas suspension system', SAE Transactions, Vol. 112, No. 6, pp.280-288.

Rakheja, S., Liu, P., Ahmed, A.K.W. and Su, H. (1993) 'Analysis of an interlinked hydropneumatic suspension', Proceedings of the 1993 ASME Winter Annual Meeting, New Orleans, USA, pp.279-288.

Smith, A.W. (2009) An Investigation into the Dynamics of Vehicles with Hydraulically Interconnected Suspensions, $\mathrm{PhD}$ thesis, University of Technology Sydney, Australia.

Smith, M.C. and Walker, G.W. (2005) 'Interconnected vehicle suspension', Proceedings of the Institution of Mechanical Engineers, Part D: Journal of Automobile Engineering, Vol. 219, No. 3, pp.295-307.

Wilde, J.R., Heydinger, G.J., Guenther, D.A., Mallin, T. and Devenish, A.M. (2005) Experimental Evaluation of Fishhook Maneuver Performance of a Kinetic Suspension System, SAE Technical Paper Series, SAE 2005-01-0392.

$\mathrm{Yu}$, J. and Kojima, E. (1998) 'Wave propagation in fluids contained in finite-length anisotropic viscoelastic pipes', Journal of the Acoustical Society of America, Vol. 104, No. 6, pp.3227-3235.

Zapletal, E. (2000) Balanced Suspension, SAE Technical Paper Series, SAE 2000-01-3572.

Zhang, N., Smith, W., Jeyahumaran, J. and Hu, W. (2007) 'Determination of mode parameters of a half-car fitted with a hydraulically interconnected suspension from simulated free decay responses', Australasian Congress on Applied Mechanics $\left(5^{\text {th }}\right)$, Brisbane, Qld., Engineers Australia.

Zhao, J. (2014) A Study of Fluid Structure Interactions in Hydraulic Piping of Passive Interconnected Suspensions, $\mathrm{PhD}$ thesis, Faculty of Engineering and IT, University of Technology Sydney, Australia.

\section{Appendix}

Field matrix of pipe section:

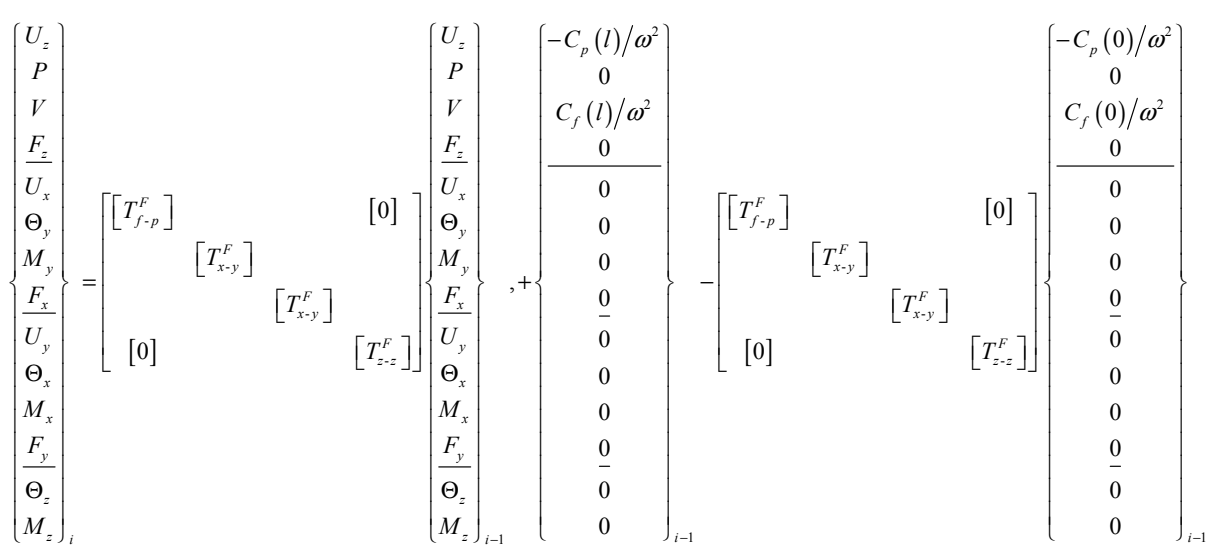

in which 
[ $\left.\mathrm{T}_{\mathrm{f}-\mathrm{p}}^{\mathrm{F}}\right]$

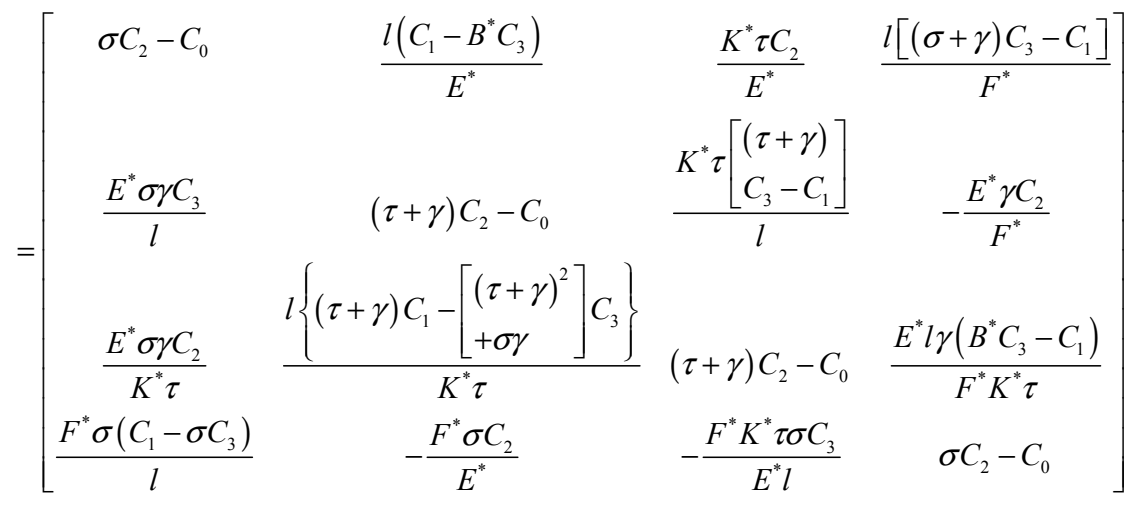

$$
\begin{aligned}
& \frac{1}{K^{*}}=\frac{1}{K}+\frac{2 r}{e_{p} E}\left(1-v^{2}\right) ; \quad E^{*}=\frac{e_{p} E}{r V} ; \quad F^{*}=A_{p} E ; \\
& \tau=\frac{\rho_{f}}{K^{*}} \omega^{2} l^{2} ; \quad \sigma=\frac{\rho_{p}}{E} \omega^{2} l^{2} ; \quad \gamma=\frac{2 \rho_{f} \nu}{E^{*}} \omega^{2} l^{2} ; \\
& \lambda_{1}^{2}=\frac{1}{2}\left(B^{*}-\sqrt{B^{* 2}-4\left(\tau \sigma+C^{\prime \prime}\right)}\right) ; \quad B^{*}=\tau+\sigma+\gamma ; \\
& \lambda_{2}^{2}=\frac{1}{2}\left(B^{*}+\sqrt{B^{* 2}-4\left(\tau \sigma+C^{\prime \prime}\right)}\right) ; \quad C^{\prime}=\text { constant; } \\
& C_{0}=\frac{\lambda_{2}^{2} \cos \lambda_{1}-\lambda_{1}^{2} \cos \lambda_{2}}{\lambda_{1}^{2}-\lambda_{2}^{2}} ; \quad C_{1}=\frac{1}{\lambda_{1}^{2}-\lambda_{2}^{2}}\left(\lambda_{2}^{2} \frac{\sin \lambda_{1}}{\lambda_{1}}-\lambda_{1}^{2} \frac{\sin \lambda_{2}}{\lambda_{2}}\right) ; \\
& C_{2}=\frac{\cos \lambda_{1}-\cos \lambda_{2}}{\lambda_{1}^{2}-\lambda_{2}^{2}} ; \quad C_{3}=\frac{1}{\lambda_{1}^{2}-\lambda_{2}^{2}}\left(\frac{\sin \lambda_{1}}{\lambda_{1}}-\frac{\sin \lambda_{2}}{\lambda_{2}}\right) \\
& {\left[\mathrm{T}_{\mathrm{x}-\mathrm{y}}^{\mathrm{F}}\right]=\left[\begin{array}{cccc}
C_{0}+\sigma C_{2} & l\left[C_{1}+(\sigma-\tau) C_{3}\right] & \frac{l^{2} C_{2}}{\eta^{*}} & -\frac{l^{3}\left[\begin{array}{l}
\sigma C_{1} \\
+\left(\sigma^{2}+\gamma\right) C_{3}
\end{array}\right]}{\eta^{*} \gamma} \\
\frac{\gamma C_{3}}{l} & C_{0}-\tau C_{2} & \frac{l\left(C_{1}-\tau C_{3}\right)}{\eta^{*}} & -\frac{l^{2} C_{2}}{\eta^{*}} \\
\frac{\eta^{*} \gamma C_{2}}{l^{2}} & -\frac{\eta^{*}\left[\begin{array}{c}
\tau C_{1}- \\
\left(\tau^{2}+\gamma\right) C_{3}
\end{array}\right]}{l} & C_{0}-\tau C_{2} & -l\left[C_{1}+(\sigma-\tau) C_{3}\right] \\
-\frac{\eta^{*} \gamma\left(C_{1}+\sigma C_{3}\right)}{l^{3}} & -\frac{\eta^{*} \gamma C_{2}}{l^{2}} & -\frac{\gamma C_{3}}{l} & C_{0}+\sigma C_{2}
\end{array}\right]} \\
& \eta^{*}=\eta_{p} E I_{p} ; \quad \tau=\frac{\rho_{p} I_{p}+\rho_{f} I_{f}}{\eta_{p} E I_{p}} \omega^{2} l^{2} ;
\end{aligned}
$$




$$
\begin{aligned}
& \sigma=\frac{\rho_{p} A_{p}+\rho_{f} A_{f}}{\kappa_{p} G_{p} A_{p}} \omega^{2} l^{2} ; \quad \gamma=\frac{\rho_{p} A_{p}+\rho_{f} A_{f}}{\eta_{p} E I_{p}} \omega^{2} l^{4} ; \\
& \lambda_{1}^{2}=\frac{1}{2}\left[\sqrt{(\sigma+\tau)^{2}+4 \gamma}+(\sigma-\tau)\right] ; \lambda_{2}^{2}=\frac{1}{2}\left[\sqrt{(\sigma+\tau)^{2}+4 \gamma}-(\sigma-\tau)\right] ; \\
& C_{0}=\frac{\lambda_{2}^{2} \cosh \lambda_{1}+\lambda_{1}^{2} \cos \lambda_{2}}{\lambda_{1}^{2}+\lambda_{2}^{2}} ; \quad C_{1}=\frac{1}{\lambda_{1}^{2}+\lambda_{2}^{2}}\left(\lambda_{2}^{2} \frac{\sinh \lambda_{1}}{\lambda_{1}}+\lambda_{1}^{2} \frac{\sin \lambda_{2}}{\lambda_{2}}\right) ; \\
& C_{2}=\frac{\cosh \lambda_{1}-\cos \lambda_{2}}{\lambda_{1}^{2}+\lambda_{2}^{2}} ; \quad C_{3}=\frac{1}{\lambda_{1}^{2}+\lambda_{2}^{2}}\left(\frac{\sinh \lambda_{1}}{\lambda_{1}}-\frac{\sin \lambda_{2}}{\lambda_{2}}\right) \\
& {\left[\mathrm{T}_{\mathrm{z}-\mathrm{F}}^{\mathrm{F}}\right]=\left[\begin{array}{cc}
\cos \lambda & \frac{l}{G^{*} \lambda} \sin \lambda \\
-\frac{G^{*} \lambda}{l} \sin \lambda & \cos \lambda
\end{array}\right] \quad G^{*}=G_{p} J_{p} ; \quad \lambda=\omega l \sqrt{\frac{\rho_{p}}{G_{p}}}}
\end{aligned}
$$

Field matrix of hose section:

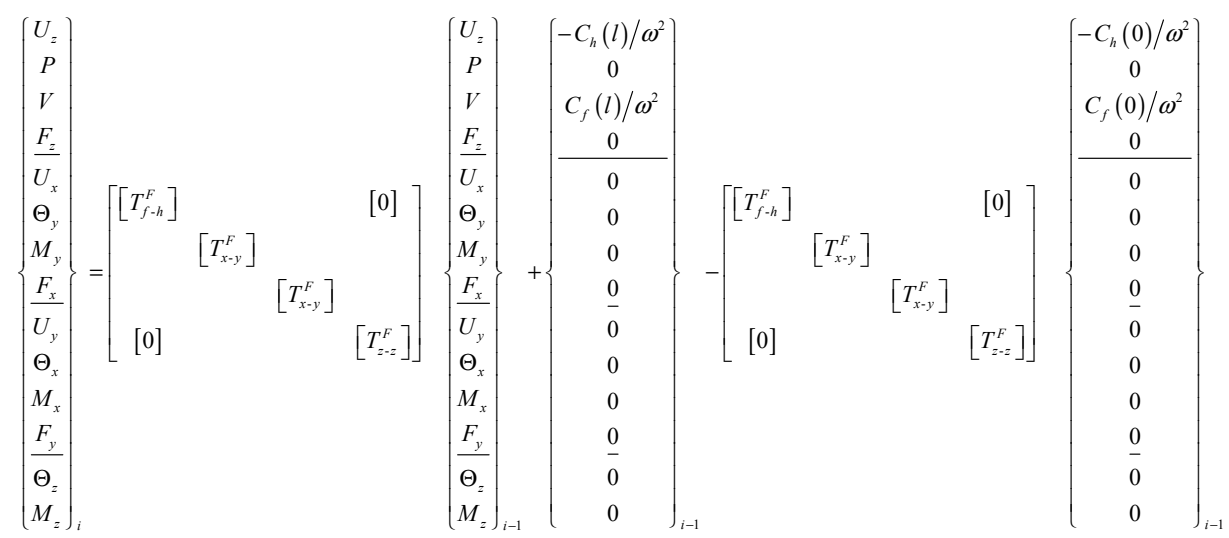

in which

$$
\begin{aligned}
& {\left[\mathrm{T}_{\mathrm{f}-\mathrm{h}}^{\mathrm{F}}\right]} \\
& =\left[\begin{array}{cccc}
\sigma C_{2}-C_{0} & \frac{l\left(C_{1}-B^{*} C_{3}\right)}{E^{*}} & \frac{K^{*} \tau C_{2}}{E^{*}} & \frac{l\left[\begin{array}{l}
(\sigma+\gamma) \\
C_{3}-C_{1}
\end{array}\right]}{F^{*}} \\
\frac{E^{*} \sigma \gamma C_{3}}{l} & (\tau+\gamma) C_{2}-C_{0} & \frac{K^{*} \tau\left[\begin{array}{l}
(\tau+\gamma) \\
C_{3}-C_{1}
\end{array}\right]}{l} & -\frac{E^{*} \gamma C_{2}}{F^{*}} \\
\frac{E^{*} \sigma \gamma C_{2}}{K^{*} \tau} & \frac{l\left\{(\tau+\gamma) C_{1}-\left[\begin{array}{l}
\left.(\tau+\gamma)^{2}\right] \\
+\sigma \gamma
\end{array}\right] C_{3}\right\}}{K^{*} \tau} & (\tau+\gamma) C_{2}-C_{0} & \frac{\left(B^{*} C_{3}-C_{1}\right)}{F^{*} K^{*} \tau} \\
\frac{F^{*} \sigma\left(C_{1}-\sigma C_{3}\right)}{l} & -\frac{F^{*} \sigma C_{2}}{E^{*}} & -\frac{F^{*} K^{*} \tau \sigma C_{3}}{E^{*} l} & \sigma C_{2}-C_{0}
\end{array}\right]
\end{aligned}
$$




$$
\begin{aligned}
& E^{*}=\frac{E_{z}}{v_{z} r_{r}} ; \quad F^{*}=E_{z} c_{r} ; \quad K^{*}=\psi_{f} K_{E} ; \quad \tau=\frac{\rho_{f}}{K^{*}} \omega^{2} l^{2} ; \\
& \sigma=\frac{\rho_{h}}{E_{z}} \omega^{2} l^{2} ; \quad \gamma=\frac{\rho_{f}\left(2 v_{z}-\psi_{h}\right)}{\psi_{f} E^{*}} \omega^{2} l^{2} ; \\
& \lambda_{1}^{2}=\frac{1}{2}\left(B^{*}-\sqrt{B^{* 2}-4\left(\tau \sigma+C^{\prime \prime}\right)}\right) ; \quad B^{*}=\tau+\sigma+\gamma ; \\
& \lambda_{2}^{2}=\frac{1}{2}\left(B^{*}+\sqrt{B^{* 2}-4\left(\tau \sigma+C^{\prime \prime}\right)}\right) ; \quad C^{\prime}=\text { constant } \\
& C_{0}=\frac{\lambda_{2}^{2} \cos \lambda_{1}-\lambda_{1}^{2} \cos \lambda_{2}}{\lambda_{1}^{2}-\lambda_{2}^{2}} ; \quad C_{1}=\frac{1}{\lambda_{1}^{2}-\lambda_{2}^{2}}\left(\lambda_{2}^{2} \frac{\sin \lambda_{1}}{\lambda_{1}}-\lambda_{1}^{2} \frac{\sin \lambda_{2}}{\lambda_{2}}\right) \text {; } \\
& C_{2}=\frac{\cos \lambda_{1}-\cos \lambda_{2}}{\lambda_{1}^{2}-\lambda_{2}^{2}} ; \quad C_{3}=\frac{1}{\lambda_{1}^{2}-\lambda_{2}^{2}}\left(\frac{\sin \lambda_{1}}{\lambda_{1}}-\frac{\sin \lambda_{2}}{\lambda_{2}}\right) \\
& {\left[\mathrm{T}_{\mathrm{x}-\mathrm{y}}^{\mathrm{F}}\right]} \\
& {\left[\begin{array}{cccc}
C_{0}+\sigma C_{2} & l\left[C_{1}+(\sigma-\tau) C_{3}\right] & \frac{l^{2} C_{2}}{\eta^{*}} & -\frac{l^{3}\left[\begin{array}{l}
\sigma C_{1} \\
+\left(\sigma^{2}+\gamma\right) C_{3}
\end{array}\right]}{\eta^{*} \gamma} \\
\frac{\gamma C_{3}}{l} & C_{0}-\tau C_{2} & \frac{l\left(C_{1}-\tau C_{3}\right)}{\eta^{*}} & -\frac{l^{2} C_{2}}{\eta^{*}} \\
\frac{\eta^{*} \gamma C_{2}}{l^{2}} & -\frac{\eta^{*}\left[\tau C _ { 1 } \left[-\left(\tau^{2}+\gamma\right) C_{3}\right.\right.}{l} & C_{0}-\tau C_{2} & -l\left[C_{1}+(\sigma-\tau) C_{3}\right] \\
-\frac{\eta^{*} \gamma\left(C_{1}+\sigma C_{3}\right)}{l^{3}} & -\frac{\eta^{*} \gamma C_{2}}{l^{2}} & -\frac{\gamma C_{3}}{l} & C_{0}+\sigma C_{2}
\end{array}\right]} \\
& \eta^{*}=\eta_{h} E_{x} I_{h} ; \quad \tau=\frac{\rho_{h} I_{h}+\rho_{f} I_{f}}{\eta_{h} E_{x} I_{h}} \omega^{2} l^{2} ; \\
& \sigma=\frac{\rho_{h} A_{h}+\rho_{f} A_{f}}{\kappa_{h} G_{h} A_{h}} \omega^{2} l^{2} ; \quad \gamma=\frac{\rho_{h} A_{h}+\rho_{f} A_{f}}{\eta_{h} E_{x} I_{h}} \omega^{2} l^{4} ; \\
& \lambda_{1}^{2}=\frac{1}{2}\left[\sqrt{(\sigma+\tau)^{2}+4 \gamma}+(\sigma-\tau)\right] \\
& \lambda_{2}^{2}=\frac{1}{2}\left[\sqrt{(\sigma+\tau)^{2}+4 \gamma}-(\sigma-\tau)\right] \\
& C_{0}=\frac{\lambda_{2}^{2} \cosh \lambda_{1}+\lambda_{1}^{2} \cos \lambda_{2}}{\lambda_{1}^{2}+\lambda_{2}^{2}} ; \quad C_{1}=\frac{1}{\lambda_{1}^{2}+\lambda_{2}^{2}}\left(\lambda_{2}^{2} \frac{\sinh \lambda_{1}}{\lambda_{1}}+\lambda_{1}^{2} \frac{\sin \lambda_{2}}{\lambda_{2}}\right) ; \\
& C_{2}=\frac{\cosh \lambda_{1}-\cos \lambda_{2}}{\lambda_{1}^{2}+\lambda_{2}^{2}} ; \quad C_{3}=\frac{1}{\lambda_{1}^{2}+\lambda_{2}^{2}}\left(\frac{\sinh \lambda_{1}}{\lambda_{1}}-\frac{\sin \lambda_{2}}{\lambda_{2}}\right)
\end{aligned}
$$




$$
\left[\mathrm{T}_{\mathrm{z}-\mathrm{z}}^{\mathrm{F}}\right]=\left[\begin{array}{cc}
\cos \lambda & \frac{l}{G^{*} \lambda} \sin \lambda \\
-\frac{G^{*} \lambda}{l} \sin \lambda & \cos \lambda
\end{array}\right] \quad G^{*}=G_{h} J_{h} ; \lambda=\omega l \sqrt{\frac{\rho_{h}}{G_{h}}}
$$

Point matrix of concentrated mass:
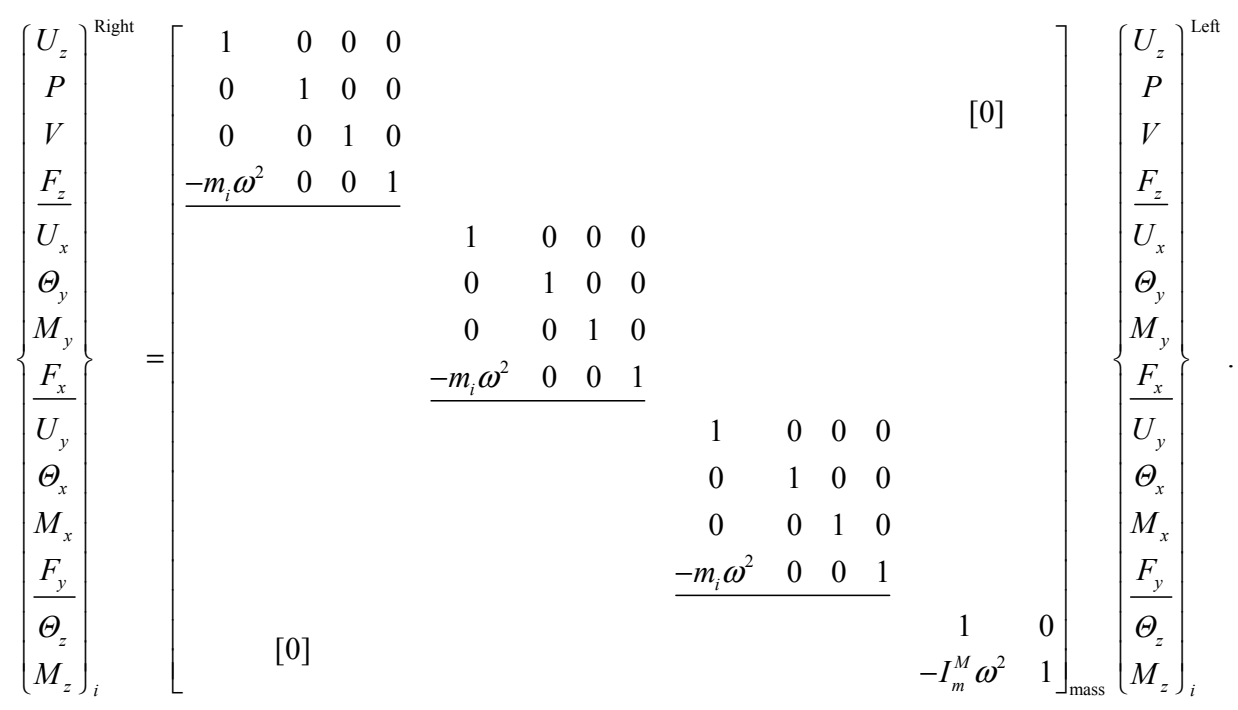

(2.3)

Point matrix of spring support:

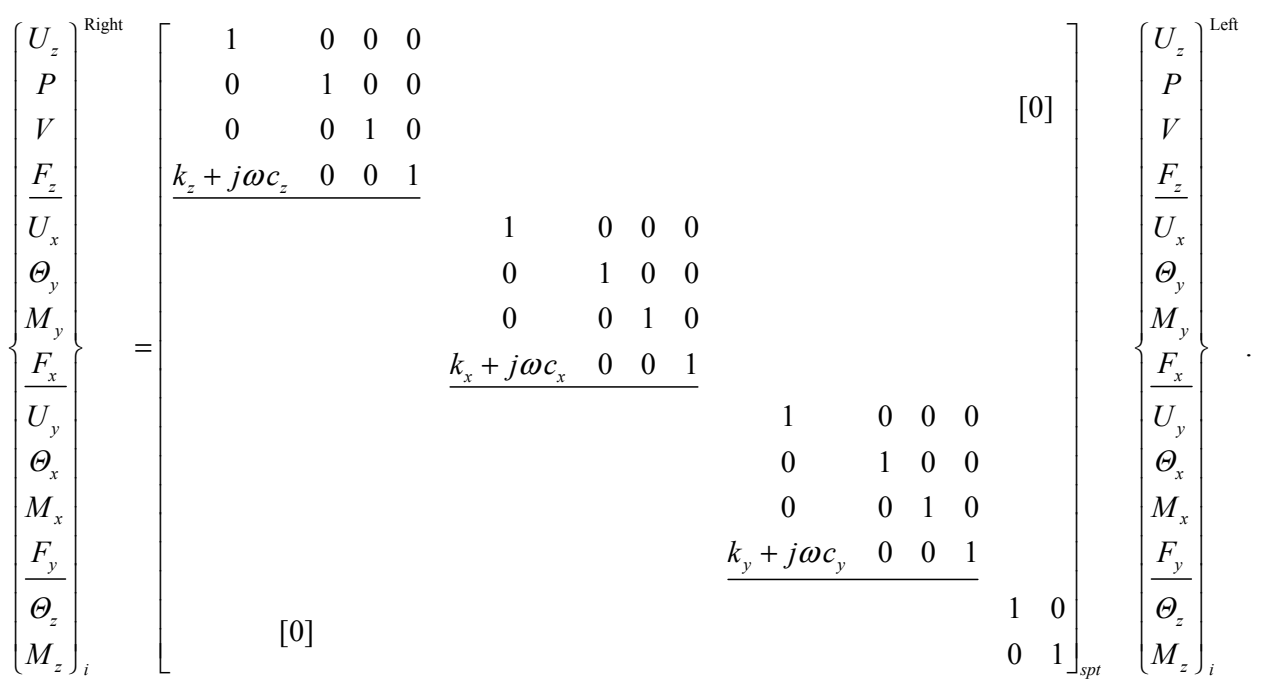


Point matrix of elbow:

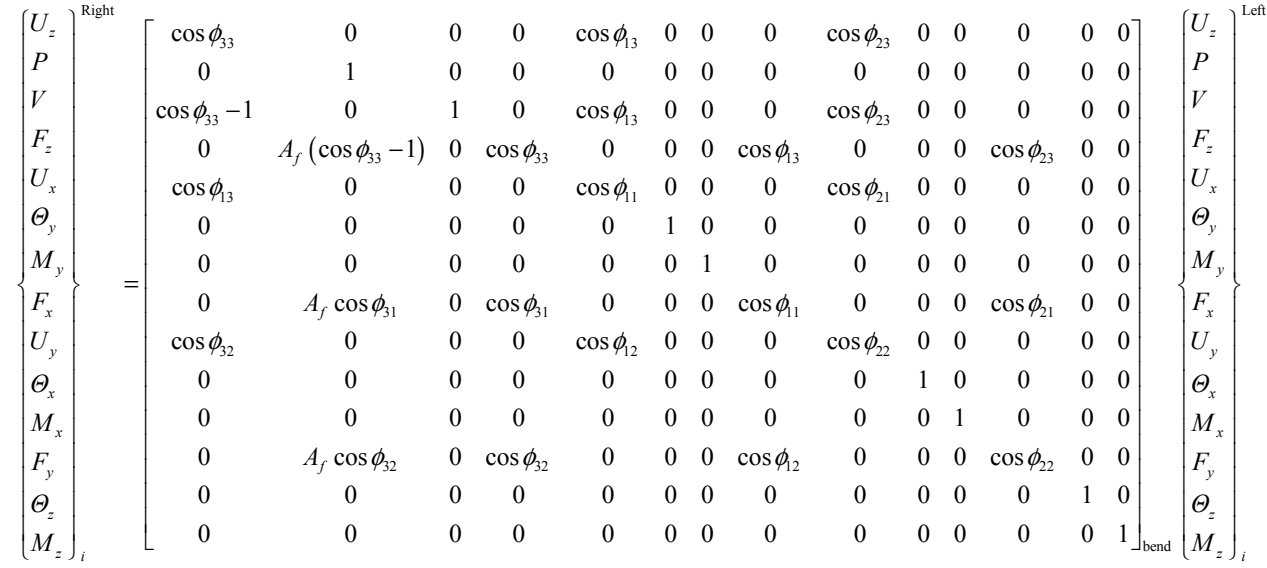

where

$$
\begin{array}{lll}
\cos \phi_{11}=x^{L} \rightarrow x^{R} ; & \cos \phi_{21}=y^{L} \rightarrow x^{R} ; & \cos \phi_{31}=z^{L} \rightarrow x^{R} ; \\
\cos \phi_{12}=x^{L} \rightarrow y^{R} ; & \cos \phi_{22}=y^{L} \rightarrow y^{R} ; & \cos \phi_{32}=z^{L} \rightarrow y^{R} ; \\
\cos \phi_{13}=x^{L} \rightarrow z^{R} ; & \cos \phi_{23}=y^{L} \rightarrow z^{R} ; & \cos \phi_{33}=z^{L} \rightarrow z^{R} .
\end{array}
$$

Point matrix of damper valve:

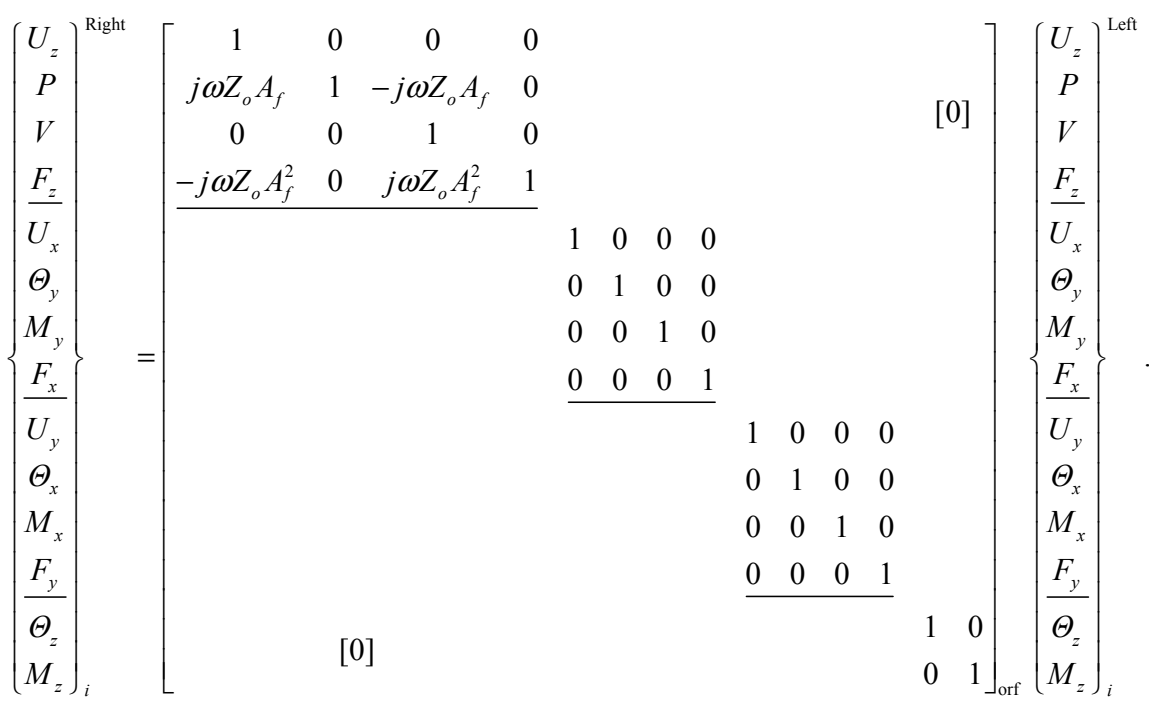


Point matrix of accumulator:

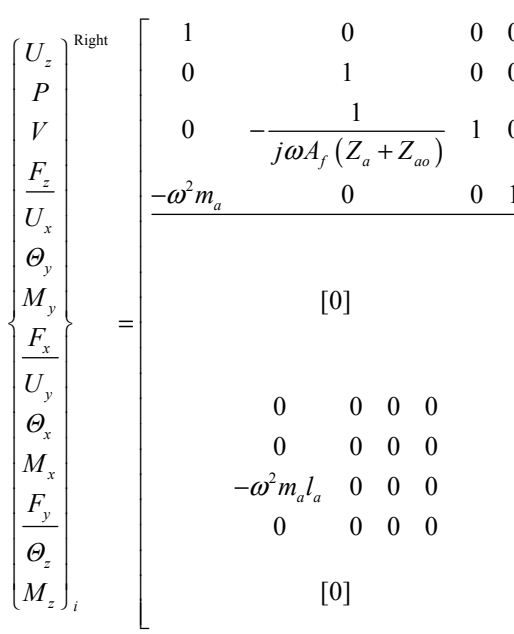

$\begin{array}{ll}0 & 0\end{array}$

0

0

$0 \quad 1$

$\begin{array}{llll}1 & 0 & 0 & 0\end{array}$

$\begin{array}{llll}0 & 1 & 0 & 0\end{array}$

$\begin{array}{llll}0 & 0 & 1 & 0\end{array}$

\begin{tabular}{llll}
$-\omega^{2} m_{a}$ & 0 & 0 & 1 \\
\hline
\end{tabular}

[0]

$\begin{array}{llll}1 & 0 & 0 & 0\end{array}$

$\begin{array}{llll}0 & 0 & 1 & 0\end{array}$

$\begin{array}{llll}m_{a} l_{a} & 0 & 0 & 0\end{array}$

$[0]$

$-\omega^{2} m_{a} \quad 0 \quad 001$

$[0]$

[0]

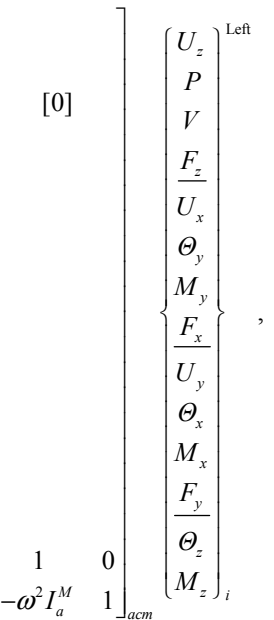

where

$C_{f}(1), C_{h}(1), C_{p}(1), C_{f}(0), C_{h}(0), C_{p}(0)$ are constants

$x, y, z$, are coordinates

$F_{x}$ : The amplitude of lateral shear force in $x$ direction

$F_{y}: \quad$ The amplitude of lateral shear force in $y$ direction

$F_{z}: \quad$ The amplitude of axial force

$M_{x}: \quad$ The amplitude of bending moment about $x$ axis

$M_{y}: \quad$ The amplitude of bending moment about $y$ axis

$M_{z}$ : The amplitude of bending moment about $z$ axis

$U_{x}: \quad$ The amplitude of lateral displacement in $x$ direction

$U_{y}: \quad$ The amplitude of lateral displacement in $y$ direction

$U_{z}: \quad$ The amplitude of axial displacement

$\Theta_{x}: \quad$ The amplitude of rotate angle about $x$ axis

$\Theta_{y}: \quad$ The amplitude of rotate angle about $y$ axis

$\Theta_{z}: \quad$ The amplitude of rotate angle about $z$ axis

$P: \quad$ The amplitude of axial pressure

$V: \quad$ The amplitude of axial displacement

$A_{f}$ : $\quad$ Cross-sectional area of fluid in pipe $\left(\mathrm{m}^{2}\right)$

$A_{h}$ : $\quad$ Cross-sectional area of hose wall $\left(\mathrm{m}^{2}\right)$

$A_{p}: \quad$ Cross-sectional area of pipe wall $\left(\mathrm{m}^{2}\right)$ 
$c_{r}: \quad$ Circumference of reinforcement of hose wall (m)

$c_{x}: \quad$ Structural damping in $x$ direction

$c_{y}: \quad$ Structural damping in $y$ direction

$c_{z}: \quad$ Structural damping in $z$ direction

$e_{h}: \quad$ Thickness of hose wall (m)

$e_{p}: \quad$ Thickness of pipe wall (m)

$E: \quad$ Young's modulus of pipe wall $(\mathrm{Pa})$

$E_{x}$ : $\quad$ Lateral Young's modulus of hose wall (Pa)

$E_{z}$ : $\quad$ Axial Young's modulus of hose wall $(\mathrm{Pa})$

$G_{h}: \quad$ Shear modulus of wall (Pa)

$G_{p}$ : $\quad$ Shear modulus of pipe wall (Pa)

$I_{f}: \quad$ Area moment of inertia of fluid in pipe $\left(\mathrm{m}^{4}\right)$

$I_{h}: \quad$ Area moment of inertia of hose wall $\left(\mathrm{m}^{4}\right)$

$I_{p}$ : Area moment of inertia of pipe wall $\left(\mathrm{m}^{4}\right)$

$I_{m}^{M}: \quad$ Mass moment of inertia $\left(\mathrm{kg} \mathrm{m}^{2}\right)$

$I_{a}^{M}: \quad$ Mass moment of inertia of the accumulator $\left(\mathrm{kg} \mathrm{m}^{2}\right)$

$j: \quad$ Imaginary unit

$J_{p}: \quad$ Polar moment of inertia of pipe wall $\left(\mathrm{m}^{4}\right)$

$K_{E}: \quad$ Modified bulk modulus of hose section (Pa)

$K^{*}: \quad$ Modified fluid bulk modulus of pipe element $(\mathrm{Pa})$

$l$ : $\quad$ Length of section or distance (m)

$m_{a}: \quad$ Mass of accumulator $(\mathrm{kg})$

$m_{i}$ : $\quad$ Mass of node $i(\mathrm{~kg})$

$r: \quad$ Inner radius of pipe wall $(\mathrm{m})$

$r_{r}: \quad$ Radius of reinforcement of hose wall (m)

$Z_{a}: \quad$ Impedance coefficient of accumulator

$Z_{a o}: \quad$ Impedance coefficient of orifice in accumulator neck

$Z_{o}: \quad$ Impedance coefficient of orifice

$\eta_{h}: \quad$ Rigidity factor for stiffness of elbow

$\eta_{p}: \quad$ Rigidity factor for stiffness of elbow of pipe

$\kappa_{h}$ : $\quad$ Shear coefficient for hollow circle cross section

$\kappa_{p}$ : Shear coefficient for hollow circle cross section of pipe 
$v: \quad$ Poisson's ratio of pipe wall

$v_{x}$ : Lateral Poisson's ratio of hose wall

$v_{z}$ : Axial Poisson's ratio of hose wall

$\rho_{f}: \quad$ Mass density of fluid $\left(\mathrm{kg} / \mathrm{m}^{3}\right)$

$\rho_{h}: \quad$ Mass density of hose wall $\left(\mathrm{kg} / \mathrm{m}^{3}\right)$

$\rho_{p}$ : $\quad$ Mass density of pipe wall $\left(\mathrm{kg} / \mathrm{m}^{3}\right)$

$\omega: \quad$ Angular frequency. 